\title{
PERCEIVED BEHAVIOURS OF LIKED AND DISLIKED ADOLESCENTS: COMPARING SPORTS TEAM AND CLASSROOM CONTEXTS
}

\author{
A thesis submitted to \\ the Faculty of Graduate Studies and Research \\ in Partial Fulfillment of the requirements for the degree \\ Masters of Arts
}

by

Geoff Wilton

Department of Psychology

Carleton University

January 2008

(C)2008 Geoff Wilton 


$\begin{array}{ll}\begin{array}{l}\text { Library and } \\ \text { Archives Canada }\end{array} & \begin{array}{l}\text { Bibliothèque et } \\ \text { Archives Canada }\end{array} \\ \begin{array}{l}\text { Published Heritage } \\ \text { Branch }\end{array} & \begin{array}{l}\text { Direction du } \\ \text { Patrimoine de l'édition }\end{array} \\ \begin{array}{l}\text { 395 Wellington Street } \\ \text { Ottawa ON K1A 0N4 }\end{array} & \begin{array}{l}\text { 395, rue Wellington } \\ \text { Ottawa ON K1A ON4 }\end{array} \\ \text { Canada } & \begin{array}{l}\text { Canada } \\ \end{array}\end{array}$

Yourfile Votre référence

ISBN: 978-0-494-36817-6

Ourfile Notre référence

ISBN: 978-0-494-36817-6

NOTICE:

The author has granted a nonexclusive license allowing Library and Archives Canada to reproduce, publish, archive, preserve, conserve, communicate to the public by telecommunication or on the Internet, loan, distribute and sell theses worldwide, for commercial or noncommercial purposes, in microform, paper, electronic and/or any other formats.

The author retains copyright ownership and moral rights in this thesis. Neither the thesis nor substantial extracts from it may be printed or otherwise reproduced without the author's permission.
AVIS:

L'auteur a accordé une licence non exclusive permettant à la Bibliothèque et Archives Canada de reproduire, publier, archiver, sauvegarder, conserver, transmettre au public par télécommunication ou par l'Internet, prêter, distribuer et vendre des thèses partout dans le monde, à des fins commerciales ou autres, sur support microforme, papier, électronique et/ou autres formats.

L'auteur conserve la propriété du droit d'auteur et des droits moraux qui protège cette thèse. $\mathrm{Ni}$ la thèse ni des extraits substantiels de celle-ci ne doivent être imprimés ou autrement reproduits sans son autorisation.
In compliance with the Canadian

Privacy Act some supporting forms may have been removed from this thesis.

While these forms may be included in the document page count, their removal does not represent any loss of content from the thesis.
Conformément à la loi canadienne sur la protection de la vie privée, quelques formulaires secondaires ont été enlevés de cette thèse.

Bien que ces formulaires aient inclus dans la pagination, il n'y aura aucun contenu manquant.

\section{Canadä}




\begin{abstract}
Reports of the aggression, prosocial behaviour and athletic ability of liked and disliked recalled peers were collected from 122 10- to 13-year-olds. Differences between perceptions of liked and disliked peers, classroom and sports settings peers, and male and female participants were investigated. Hypotheses were guided by the person-group similarity hypothesis and the self-categorization hypothesis. Liked peers were perceived to be significantly more prosocial, athletic and less aggressive than disliked peers. Participants reported peers from sports teams as higher in prosocial behaviour and athletic ability than peers from classrooms. Males reported more aggression than females. A gender by setting by status interaction effect was significant for aggression. The largest effects were between liked and disliked peers suggesting that the behaviours of individuals are the most important consideration when studying social status among peers. Results also support the importance and further investigation of differences between social settings and genders.
\end{abstract}




\section{Acknowledgments}

Anne Bowker my thesis supervisor deserves a big thank you. Thank you for providing an ideal learning environment. Your support during difficult courses and difficult stages of my research were essential to my success. Thank you most of all for your patience when I was unsure of my commitment to the program. I also greatly appreciate your feedback which allowed me to develop my own writing and research style, which demanded personal excellence but was never unreasonable or perfectionistic.

Thank you Rob Coplan, Tina Daniels and Virginia Caputo for forming my thesis committee. Rob and Tina, your contributions at my prospectus and my defence challenged me to reach optimal performance but were always clearly aimed at improving my research. Thank you for your suggestions which succeeded in improving the research method and the discussion of my results. Thank you also for providing engaging and applicable courses.

Mom and Dad, thank you for the myriad forms of support you have provided throughout my education. Thank you for all the time and energy spent helping to recruit participants and form contacts. Thank you for trusting that I will succeed in the end.

Thank you to all of the participants and parents of participants of my study. Your willingness to assist me with no expectation of anything in return is the best example of altruism I can imagine.

Finally I want to express a big thank you to all of my friends. If it weren't for a healthy dose of peer pressure backed-up by logic and several voices saying, "you can do it," I would not have persevered. 
Table of Contents

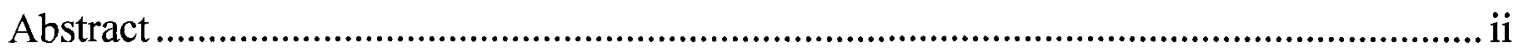

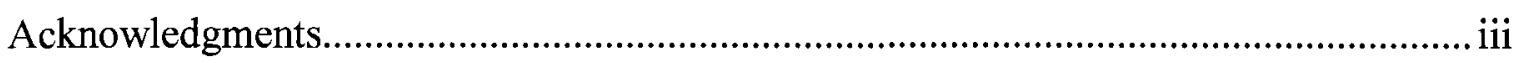

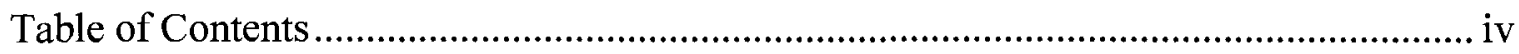

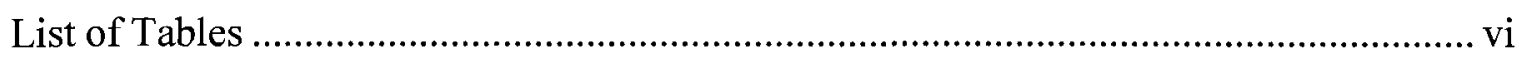

Perceived Behaviours of Liked and Disliked Adolescents: Comparing Sports Team and

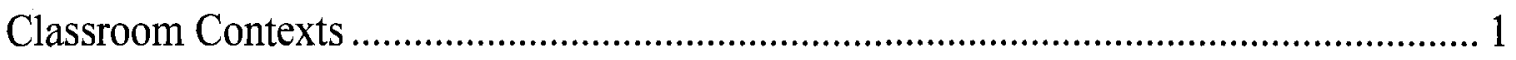

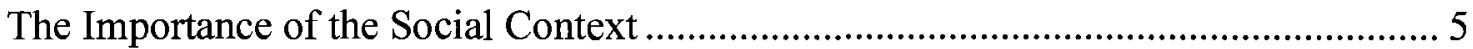

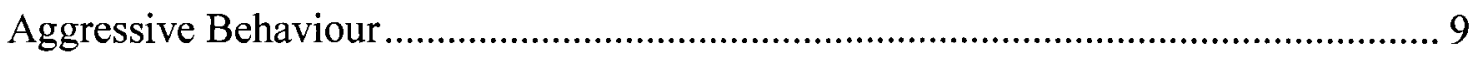

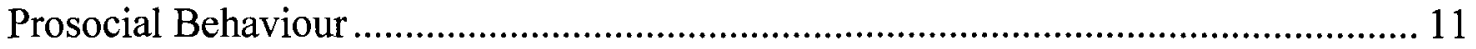

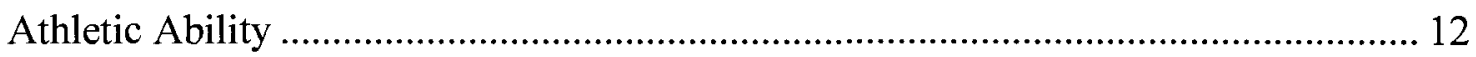

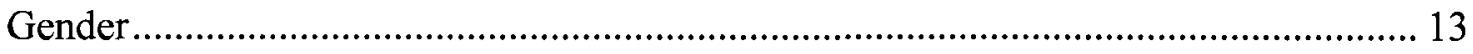

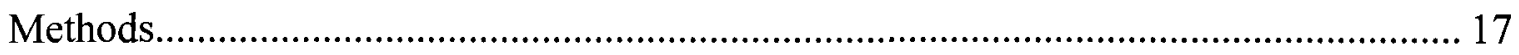

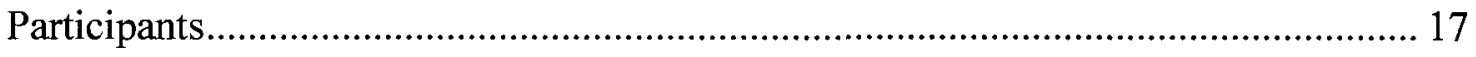

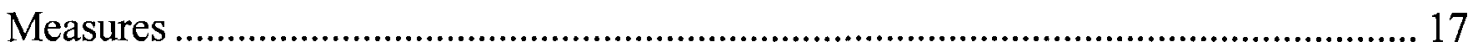

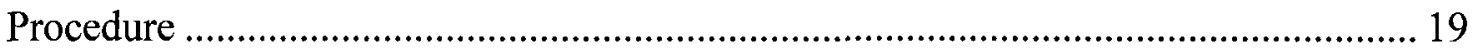

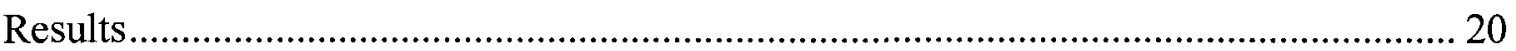

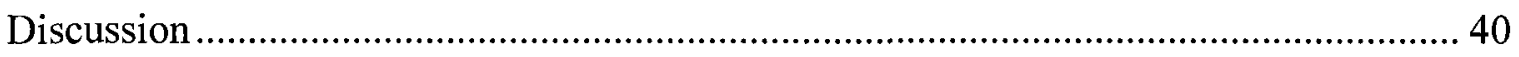

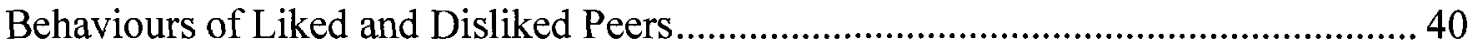

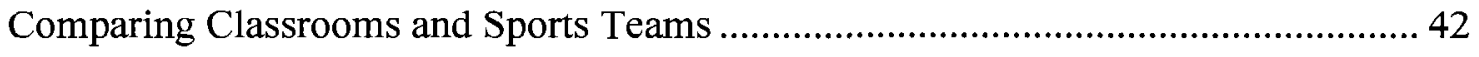

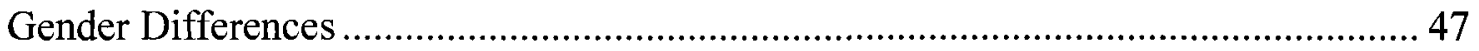

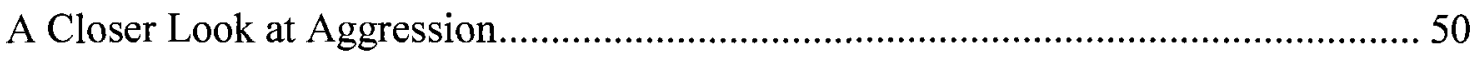

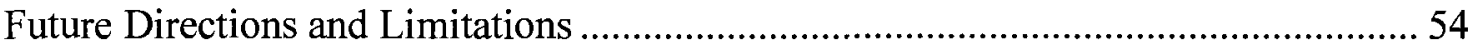




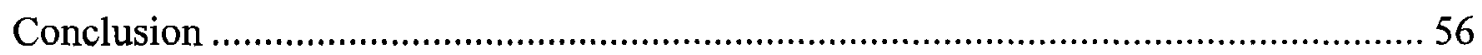

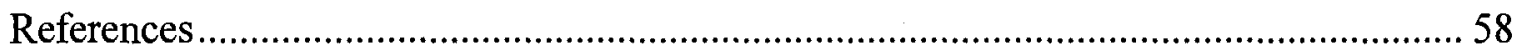




\section{List of Tables}

Table 1 Results of the MANOVA tests for all main effects and interactions effects.

Table 2 Results of the ANOVA tests for all main effects and interaction effects on aggression.

Table 3 Results of the ANOVA tests for all main effects and interaction effects on prosocial behaviour.

Table 4 Results of the ANOVA tests for all main effects and interaction effects on athletic ability. 25

Table 5 Means and standard deviations of the three behaviours in each of the social status categories.

Table 6 Means and standard deviations of the three behaviours in each of the social setting categories.

Table 7 Means and standard deviations of the three behaviours as perceived by male and female participants.

Table 8 Results of the ANOVA tests for all main effects and interaction effects on physical aggression. 34

Table 9 Results of the ANOVA tests for all main effects and interaction effects on relational aggression. 


\section{List of Figures}

Figure 1. Social status by social setting interaction plots displaying cell means of aggression as perceived by male and female participants.

Figure 2. Social status by social setting interaction plot displaying cell means of

relational aggression.

Figure 3. Social status by social setting interaction plots displaying cell means of physical aggression as perceived by male and female participants. 


\section{List of Appendices}

Appendix A -Letter Requesting Participation of Sports Team ........................................ 65

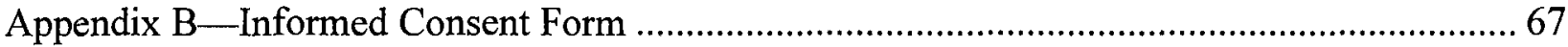

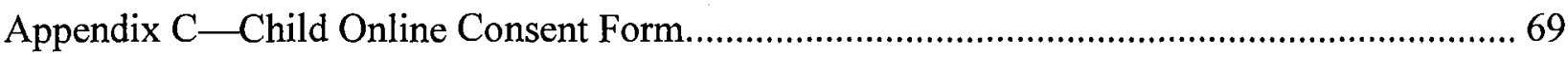

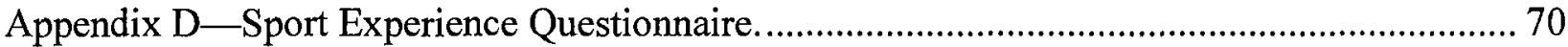

Appendix E_Peers' Behaviour Questionnaire. .......................................................... 71 
Running Head: BEHAVIOURS OF LIKED AND DISLIKED ADOLESCENTS

Perceived Behaviours of Liked and Disliked Adolescents: Comparing Sports Team and

\section{Classroom Contexts}

The experience of being disliked by one's peer group and seldom being liked is hurtful for any person and occurs frequently during childhood. In peer relations research, children who share this experience are called rejected (Coie, Dodge, and Coppotelli, 1982). Virtually everyone can remember as a child seeing someone who did not fit in with the group. Many people can also remember seeing a group of children treat another in a hurtful way. Rejected children often face peers who ignore, exclude, deny access to resources or others, threaten, mock, dominate and physically, relationally, and verbally victimize them (Asher, Rose, \& Gabriel, 2001). They also receive less positive treatment from peers (Asher, et al., 2001). No matter what the behaviour used to reject a child, the results are never positive for the individual (Twenge \& Baumeister, 2005; Williams \& Govan, 2005). Following food and shelter, a sense of belonging is one of the most fundamental human needs (Baumeister \& Leary, 1995). Few rejected children feel a sense of belonging to their peer group.

Positive social relations with peers may be particularly important during childhood and early adolescence due to the social development that takes place during these periods, and to the unique contributions peer relationships provide beyond the influence of relationships with family and professionals (Hartup, 1983). Because rejected individuals experience relatively infrequent positive peer interactions, peer rejection during childhood is associated with a broad range of negative outcomes. Specifically, peer rejection has been associated with school dropout, truancy, depression, anger, counter aggression (Parker \& Asher, 1987), substance abuse, antisocial behaviour (Coie, 
Behaviours of liked and disliked adolescents 2 1990) conduct disorder (Coie, 2004), and increasing loneliness (Boivin, Hymel, \& Bukowski, 1995). The broader categories of externalizing and internalizing problems have also been associated with peer rejection (Ladd, 2006). Many theoretical perspectives attempt to explain the relationships among individuals' behaviours, peer rejection and development of externalizing and internalizing problems. Although behaviours such as aggression and social withdrawal have been associated with externalizing and internalizing problems, Ladd (2006) argued that peer rejection contributes to both externalizing and internalizing maladjustment in ways that are unique to aggression and social withdrawal. In addition to reduced social interaction which limits the benefits provided by the peer group, these outcomes are likely also due to overly harsh treatment and criticisms directed to rejected children. Children direct mistreatment to their rejected peers at elevated levels (Buhs \& Ladd, 2001). Furthermore, rejected children are subjected to their peers' critical reputation biases and biased judgements which unfairly portray the rejected children (Koslin, Haarlow, Karlins, \& Pargament, 1968).

Such results indicate that researchers in the area of peer relations are well aware of the need to improve the lives of rejected children and promote greater inclusion of them within peer groups. Assuming that rejected children will learn from their mistakes is not good enough. While negative feedback from peers can improve social skills and foster the development of emotion regulation and conflict resolution skills, "children rarely learn useful skills from chronic peer problems" (Bierman, 2004, p.11). Rejected children become even less likely to be included over time since social exclusion has been suggested to cause increased aggression (Prinstein \& Cillessen, 2003), self-defeating behaviours such as choosing unhealthy behaviours and procrastinating (Twenge, 
Catanese, \& Baumeister, 2002), and decreases in prosocial behaviour (Twenge, Baumeister, DeWall, Ciarocco, Bartels, 2007) and cognitive performance (Baumeister, Twenge, \& Nuss, 2002). Thus, the relationship between peer rejection and associated behaviours may follow a cyclical pattern in which maladaptive behaviours contribute to peer rejection which contributes to further maladaptive behaviours (Ladd, 2006). The assistance of professionals to improve the social lives of these children is necessary, and developmental psychologists have helped fill this role by providing a base of research.

Many studies of peer relations have focused on the behaviours of individuals, examining behavioural characteristics as an explanation of social status (e.g. Newcomb, Bukowski, \& Pattee, 1993; Pope, Bierman, \& Mumma, 1991; Prinstein, \& Cillessen, 2003; Evans \& Roberts, 1987). Studies that use peer reports typically involve a) collecting nominations of who is liked and disliked within a group of participants selected from the classroom and b) measurement of a variety of behaviours which may explain each individual's status (e.g. rejected, neglected, controversial, and popular). Coie, Dodge and Copotelli (1982) and Newcomb and Bukowski (1984) pioneered this method, allowing for the exploration of behavioural profiles of several different social status categories. For example, aggressive individuals tend to frequently be nominated as disliked and prosocial individuals tend to frequently be nominated as liked (Coie, et al., 1982). Athletic competence is also related to higher levels of social status (Weiss \& Duncan, 1992; and Chase \& Dummer, 1992).

The behaviours of individual participants were the focus of these types of studies, and they generated a substantial amount of research which was later applied to coaching strategies and other interventions designed to assist rejected children in developing more 
Behaviours of liked and disliked adolescents 4 adaptive behaviours (Beirman, 2004). However, "social behaviour is never a function of the individual alone" (Maccoby, 1990, p.513). The social circumstances surrounding peer rejection seem to involve at least two elements besides the behaviour of the rejected individual. Peer rejection necessarily involves a peer group that rejects the individual, as well as the social context in which the group formed. Peer relations literature has been criticized for not considering the social context (e.g. Wright, Giammarino, \& Parad, 1986; Chang, 2004).

In response to such criticism, researchers and theorists have considered social factors in a few key ways. Firstly, Gazelle (2006) investigated a child by environment model of peer relations. She found that how anxiously solitary children fared in terms of depression and peer victimization depended upon class climate, whether a classroom functions smoothly and harmoniously and is a generally positive atmosphere, or it is prone to conflict, disruption, and disorganization (Gazelle, 2006). Anxiously solitary children experienced less depression and less peer victimization in positive class climates compared to negative climates (Gazelle, 2006). Secondly, social factors in peer relations have been considered in cross-cultural studies. While sociability-leadership behaviour was positively related to peer acceptance, and aggressive-disruptive behaviour was positively related to peer rejection in both Chinese and Canadian samples, shynesssensitivity was positively associated with peer acceptance for Chinese children but negatively associated with acceptance for Canadian Children (Chen, Rubin, \& Sun, 1992). Chen and his colleagues (1992) concluded this difference was due to the Chinese culture valuing and encouraging sensitive, cautious, and inhibited behaviour while the Canadian culture views those behaviours as signs of social immaturity, fearfulness and 
Behaviours of liked and disliked adolescents 5

deviance. Finally, to give greater consideration to social factors in the study of peer relations, studies have tested the person-group similarity hypothesis. The person-group similarity hypothesis proposes that the frequency of a behaviour within a group will often determine how it will be related to the social status of individuals (Wright, et al., 1986; Boivin, Dodge, \& Coie, 1995; Stormshak, Bierman, Bruschi, Dodge, Coie, \& the Conduct Problems Prevention Research Group, 1999; Chang, 2004). Results have indicated, as expected, that the relationship between aggression and peer rejection is weaker in highly aggressive groups (Wright et al., 1986; Stormshak, et al., 1999; Chang, 2005).

The present study proposes to extend past research by exploring possible differences among two social settings: the school classroom and sports teams. These two social contexts were compared regarding adolescents' perceptions of behaviours associated with being liked and disliked by the peer group. Differences would support the notion that the social context is an important factor to consider when studying peer relations and designing interventions for those children who are rejected by their peers. Such results would demonstrate that in the perceptions of adolescents the behaviours that relate to acceptance or rejection may differ from one context to the next, indicating that some groups may be more accepting of individuals who are rejected by other groups. For example, aggression and athletic ability may be more valued in a sports context than classrooms.

The Importance of the Social Context

Both the Self-Categorization Theory and the Person-Group Similarity Hypothesis support the importance of considering the social context when investigating the 
Behaviours of liked and disliked adolescents 6 behaviours that are associated with peer rejection or acceptance. In both cases, the norms of the group are important to consider.

Normative beliefs may be defined as "an individual's cognitions about the acceptability or unacceptability of behaviours that regulate his or her corresponding behaviours" (Guerra, Huesmann, \& Hanish, 1995, p. 141). According to the selfcategorization theory, as summarized by Parkinson, Fischer and Manstead (2005), people who conform to a set of normative behaviours and beliefs that promote the group's goals are "personally attractive" and good candidates for inclusion. The group emphasizes the similarities among group members and emphasizes the differences of non-members to clarify who should be included and to justify excluding those who differ from the normative beliefs and behaviours (Parkinson, et al., 2005). Often, the group will overemphasize differences by developing critical reputation biases and biased judgments of the rejected child (Koslin, et al., 1968). Members of social groups tend to share normative beliefs and expect some level of conformity to those norms. Exclusion becomes a method of boundary control, a means of maintaining the definition of the group and its norms, and ultimately determines its survival (Levine, Moreland, \& Hausman, 2005). Thus, according to the Self-Categorization Theory, peer rejection serves the functions of affirming the norms of the group, restricting membership to those who will help the group reach its goals, thereby helping the group survive.

Of course, various groups form with different intended goals. A social group may form with the purpose to help its members to reach tangible goals or simply the goal of social interaction (Parkinson, et al., 2005). Both tangible goals and social interaction seem to be the goals of children joining sports teams. Winning competitions, having fun, 
Behaviours of liked and disliked adolescents

and developing new friendships are frequent reasons provided by children for

participating in sports (Murphy, 1999; Hacker, 2005). However, different children will

likely be attracted to, and included in sports teams than other social groups because of

norms and values that differ among social settings. For example, aggression and athletic

ability may be more highly valued in sports teams than in classrooms, and children who

are perceived to display aggression and possess a high athletic ability will be more likely

to be perceived as well accepted in a sports setting than a classroom setting. Other

behaviours such as prosocial behaviour will likely be important across social groups,

since prosocial behaviour is helpful in all contexts to develop positive affiliations

(Hartup, 1983; Wright et al., 1986).

Although peer relations researchers rarely refer to the Self-Categorization Theory, their use of the Person-Group Similarity Hypothesis echoes many similar ideas.

According to the Person-Group Similarity Hypothesis, the relationship between an

individual's behaviour and his or her social status may depend on how common that behaviour is in the peer group (Wright, et al., 1986; Boivin, et al., 1995; and Stormshak, et al., 1999; Chang, 2005). Some behaviours may follow a dissimilarity rule such that an individual who displays a behaviour in a group in which that behaviour is non-normative or uncommon is likely to be rejected from the group; a child who displays a behaviour that is normative in the group will be more likely to 'fit in' and be accepted (Wright, et al., 1986). This is similar to the Self-Categorization Theory. Those who do not reflect the norms of the group and do not contribute to the goals of the group are the ones that are expected to be rejected. 
Behaviours of liked and disliked adolescents 8 According to these perspectives, finding a social context which values the behaviours of an individual child may be an effective way to prevent the social exclusion of the individual. This possibility has been debated in the peer relations literature. Coie and Kupersmidt (1983, p.1412) contested the person-group similarity hypothesis by stating that "the social problems [socially rejected children] encounter in school are not simply an accident of group composition or circumstance," that the behaviours of the rejected children determine social status. Wright and colleagues (1986) responded by pointing out that the Coie and Kupersmidt research included only children recruited from school settings and that settings with different norms may result in a different set of behaviours being associated with peer rejection. Unfortunately, this criticism can be applied to many studies since the majority of peer relations research has been conducted within the school system (Bierman, 2004), ignoring possible differences among social settings.

The present study aims to extend past research by investigating the possible role of social setting in peer relations by investigating two different settings. Participants will be asked to think of liked and disliked peers in classroom and sports team settings. The classroom represents a setting which almost all youth experience and reflects the majority of peer relations literature, providing a link to the foundation of past research to which the other settings can be compared. Sports teams represent an extracurricular group that likely differs from the classroom setting in terms of the norms and values that are acceptable.

Past research has supported the proposal that settings often differ. Classrooms have been found to differ in their climates and characteristic behaviours to such an extent 
Behaviours of liked and disliked adolescents 9

that the behaviours that relate to peer acceptance and peer rejection differ (Chang, 2005;

Gazelle, 2006). Sports teams are expected to differ from the more general classroom settings in their norms, and this is expected to be reflected in the perceptions of participants' peers from each setting. For example, research by Bredemeier and colleagues has suggested that sports teams and athletes are generally more accepting of aggression defined as intent to cause injury (Bredemeier, \& Shields, 1984), and that those interested in sports are more likely to be aggressive (Bredemeier, Weiss, Shields, \& Cooper, 1986). Furthermore, research within the sports context has been suggested to be lacking, especially considering the importance sports play in youths' lives.

Typically, peer relations research has overlooked differences between social settings such as sports teams and classrooms, focussing on the behaviour of individuals (Wright, et al., 1986; Chang, 2004). While this research may have neglected possible roles of the social setting, it has generously contributed to understanding and assisting rejected children by investigating the behaviours that tend to be associated with rejection in children's peer groups, and by developing strategies to help them develop more adaptive behaviours. Within this research, two behaviours are particularly prominent: aggression and prosocial behaviour.

Aggressive Behaviour

Aggression may be defined as any act that is intended to cause harm to another person (Coie \& Dodge, 1988; Perry, Perry \& Kennedy, 1992). Aggression is one of the most common and consistent factors associated with peer-rated social status (Coie, 1990, Newcomb, et al., 1993). However, researchers discovered that children could be aggressive but not be rejected (Bierman, 1986), and that highly aggressive children can 
Behaviours of liked and disliked adolescents 10 be very popular (Rodkin, Farmer, Pearl \& Van Acker, 2000). Further confusion occurred due to results indicating that aggression is consistently related to rejection but not to acceptance (Coie, et al., 1982). Rather than the aggressive behaviour causing someone to be rejected, other researchers have suggested that peer rejection causes someone to become aggressive (Baumeister \& Leary, 1995; Prinstein \& Cillessen, 2003), that maladjusted behaviours precede both aggression and peer rejection, or that aggression and peer rejection exacerbate maladjusted behaviours and vice versa cyclically (Ladd, 2006).

Investigating differences between social settings in the relationship between aggression and social status as perceived by adolescents may offer important insight into this relationship and help clear some of the confusion. Research has supported the person-group similarity hypothesis regarding aggression. As levels of aggression in groups increases, the degree to which aggression is related to peer rejection decreases (Wright, et al., 1986; Boivin, et al., 1995; and Stormshack, et al., 1999). Children within some settings may be more accepting of aggressive behaviour than other settings. Research would suggest that physical aggression is viewed as more acceptable in sports contexts (Bredemeier, \& Shields, 1984) and that sports participants behave more aggressively (Bredemeier, et al., 1986). The present study thus hypothesized that disliked peers in sports teams would be described by the participants as less aggressive than disliked peers in classrooms. Furthermore, liked peers in sports were expected to conform to the aggressive norms of the sports team context, and thus liked peers were hypothesized to be described as more aggressive in sports teams than liked peers in 
Behaviours of liked and disliked adolescents 11 classrooms. The difference between liked and disliked peers' aggression as perceived by the participants is therefore hypothesized to be smaller in sports teams than classrooms.

\section{Prosocial Behaviour}

Prosocial behaviour, like aggression, is strongly related to children's social status. The ability to cooperate, share and interact positively with peers - the ability to act prosocially - has long been suggested to be an important skill to effectively interact and form positive relationships with peers across development (Hartup, 1983) and across contexts (Wright et al., 1986). A meta-analysis conducted by Newcomb and colleagues (1993) found that popular children displayed the most prosocial behaviours including problem solving, positive social actions, positive social traits, friendship relations, and overall sociability. They also found that the rejected children showed less prosocial behaviour than children of an average status in the areas of social interaction, positive social actions, positive social traits, friendship relations, adult interaction, and overall sociability (Newcomb, et al., 1993).

Prosocial behaviour seems to be related to social status differently than aggression. While aggression is associated with peer rejection, prosocial behaviour is associated with acceptance (Hartup, Glazer, \& Charlesworth, 1967). Positive behaviours such as acting prosocially appear to be related to measures of peer acceptance, while negative behaviours are related to measures of rejection. Thus, an individual's display of prosocial behaviour is likely to contribute to the prediction of his or her social status in ways that are unique to aggression, and is an important behaviour to include in studies of peer relations. 
Behaviours of liked and disliked adolescents 12

The present study hypothesized that all social settings should value prosocial

behaviour equally. This follows from past research which hypothesized prosocial behaviour to be valued across all social groups (Stormshak, et al., 1999; Boivin, et al., 1995), and that the relationship between prosocial behaviour and social status is less variable from group to group than social withdrawal and aggression (Chang, 2004).

Although some studies have found that prosocial behaviour as it relates to social status depends to some extent on the levels of prosocial behaviour in the group (Chang, 2004; Boivin, et al., 1995), others have confirmed the hypothesis that prosocial behaviour is related to higher social status regardless of the level within the group (Stormshak, et al., 1999). Due to such results and others suggesting that the relationship between prosocial behaviour and social status is relatively stable across groups, any differences between the groups' responses to prosocial behaviour as perceived by the participants was expected to be too subtle for the present study to detect.

\section{Athletic Ability}

In addition to aggression and prosocial behaviour, athletic ability is important for the purposes of the present study. Research has supported that athletic ability and physical skills are related to attaining higher levels of social status (Weiss \& Duncan, 1992; Chase \& Dummer, 1992). However, athletic ability has received less research attention than aggression and prosocial behaviour. Physical skills are highly valued during childhood. When asked what would make oneself or another person popular, boys responded that sports participation was the most important determinant for both personal and others' popularity (Chase, \& Dummer, 1992). In addition to popularity, children who score high in measures of physical competence tend to also score high on measures of 
Behaviours of liked and disliked adolescents 13

peer acceptance (Weiss, \& Duncan, 1992). While these results suggest a relationship between athletic ability and high social status, a similar relationship exists for children of lower social status. Rejected children have been shown to be rated as worse on athletic ability than popular children (Johnstone, Frame, \& Bouman, 1992). Also social status has been shown to improve with physical fitness following sports-fitness training (Gross, Johnson, Wojnilower, \& Drabman, 1985). Athletic ability is therefore an important factor in peer relations research in general.

Athletic ability may be an especially important determinant of social status within the context of sports teams since it contributes directly to the goals and purposes of sports teams. Classrooms on the other hand may value athletic ability, but athletic ability will contribute to the goals of this context less frequently than sports teams. Thus, the present study hypothesized that athletic ability would follow the person-group similarity hypothesis. Peers recalled by the participants who were liked within sports teams were expected to be described as more athletically competent than liked peers within classrooms. Also, disliked peers within sports teams were expected to be perceived as lower in athletic competence scores than within classrooms. Thus, the difference between liked and disliked peers' athletic ability as perceived by the research participants was hypothesized to be smaller in classrooms than in sports teams.

\section{Gender}

While the present study aimed to explore the behaviours that relate to being liked or disliked within sports teams and classrooms, it also offers the opportunity to explore gender differences in these behaviours. Gender is important to consider. Possible gender by social status interaction effects on aggression and athletic ability, gender by social 
Behaviours of liked and disliked adolescents 14 setting interaction effects on aggression and athletic ability, and gender main effects on the set of behaviours were examined.

A distinction between sex and gender is applicable and encouraged within studies of social interactions (Doyle \& Paludi, 1998). The term 'gender' was chosen over 'sex' for the present study. Gender refers to socio-cultural differences between boys and girls in what is considered to be acceptable behaviour (Unger, 1979). The present study aimed to emphasize the social differences between male and female participants' perceptions of their peers and potential differences in the social experiences of male and female participants. The use of 'sex' should be restricted to discussion of biological differences (Unger, 1979). Thus, the term 'sex' was inappropriate for the purposes of the present study.

Interactions involving gender seemed likely because male and female participants may differ in their perceptions of the behaviours displayed by peers of different social statuses, and male, female and mixed-sex social settings may differ in the normative levels of the behaviours investigated in the present study. The behaviours of boys and girls depends on whether the context is mixed- or same-sex; the behaviours of both boys and girls depend on whether or not the opposite sex is also present, and boys and girls greatly prefer interacting within gender-segregated groups during late childhood and early adolescence (Maccoby, 1990). The preference to engage in interactions with members of the same sex may exacerbate differing styles of interaction. Girls tend to use enabling interaction styles which help them to develop strong interpersonal relationships, but boys tend to use restrictive interaction styles which contribute to social organization 
Behaviours of liked and disliked adolescents 15 according to dominance hierarchies (Maccoby, 1990). This suggests that the behaviours in which boys and girls engage likely differ as well.

The person-group similarity hypothesis suggests that behaviours that are nonnormative are likely to differentiate between liked and disliked children to a greater extent than behaviours that are normative within a group. If the normative levels of the behaviours differ between male, female and mixed-sex groups, then gender and social setting are likely to interact. The perceptions of the behaviours in classrooms and sports teams may differ and this difference may depend on the gender of the participant. Furthermore, if males and females differ in their perceptions of the acceptability of the behaviours, then social status and gender will likely interact. The perceived difference between liked and disliked peers on a given behaviour was expected to depend upon the gender of the participant.

While the difference between levels of aggression among boys and girls are debated and results may be inconsistent across types of aggression, boys are more likely to behave in physically aggressive ways and to threaten physical aggression than girls (Maccoby, 1990). Furthermore, aggression along with toughness and violence are viewed by society as normative of males while gender norms of females emphasize openness, caring and other behaviours related to mothering (Doyle \& Paludi, 1998). Following the person-group similarity hypothesis, this would suggest that participants would perceive boys' groups as more aggressive and more accepting of aggression than girls' groups. In accordance with this, Lancelotta and Vaughn (1989) found that aggression was negatively correlated with peer acceptance to a greater extent for girls than for boys. Consistent with these results, the present study hypothesized that girls would perceive 
Behaviours of liked and disliked adolescents 16 disliked peers as more aggressive than boys and perceive liked individuals as less aggressive than boys. Thus, the perceived difference between liked and disliked peers' aggression was expected to be greater for girls than boys.

Athletic ability also seemed likely to be valued differently by boys and girls, and as a result, differentially related to perceptions of liked and disliked peers. According to Greendorf, Lewko and Rosengren (1996), the sports context is perceived primarily as the domain of boys, socializing them in their gender roles, while girls report unequal opportunities to participate. Girls are more likely to report being motivated by personal performance goals, while boys tend to be motivated by winning and to be more competitive in a sports context (Gill \& Deeter, 1988). Maccoby (1990) also suggested that dominance and competition are more important motives for boys than girls in general. These results suggest that boys may value behaviours that contribute to winning and dominating the opposition, namely athletic ability, to a greater extent than girls. Thus, the present study hypothesized a gender by status interaction effect for athletic ability. Boys were expected to perceive liked peers as higher in athletic ability than girls, and disliked peers would be perceived to have lower levels of athletic ability when reported by boys than when reported by girls.

Unlike aggression and athletic ability, the relationship between prosocial behaviour and social status as perceived by the participants was not expected to depend on the normative levels within different social settings or genders. As described earlier, prosocial behaviour was hypothesized to be necessary for developing positive social relationships equally across social groups (Hartup, 1983; Wright, et al., 1986). Liked individuals were hypothesized to be reported as behaving prosocially equally across 
Behaviours of liked and disliked adolescents 17

social contexts and genders. Perceived levels of prosocial behaviour of disliked

individuals were also hypothesized to remain constant across social contexts and genders.

Methods

\section{Participants}

A total of 122 ( 64 male and 58 female) participants between 10 and 13 years of age were recruited from sports and science day camps, sports teams, and through networking with personal contacts and other participants. All participants had written parental permission to participate.

Measures

The present study aimed to compare the social settings of sports teams and classrooms in terms of the behaviours that liked and disliked young adolescents are perceived by their peers to display. Participants were asked to retrospectively think of liked and disliked individuals in both a school classroom and a sports team. Following each request to think of a liked or disliked peer from a specific context, a list of behavioural descriptions were presented to measure the aggressive, prosocial and athletic behaviours of each peer. Liked peers were requested by asking the participants to, a) "Think of someone you know in a classroom at school who was liked by lots of people in the class." and b) "Think of someone you know in a sports team who was liked by lots of people on the team." Similar items requested participants to respond regarding two disliked peers by asking, a) "Think of someone you know in a classroom at school who was disliked by lots of people in the class." and b) "Think of someone you know in a sports team who was disliked by lots of people on the team." 
Behaviours of liked and disliked adolescents 18

The behavioural measures that followed each of these four questions consisted of a modified version of the Extended Class Play (ECP; Burgess, et al., 2006) and a modified version of the Physical Self-Description Questionnaire (PSDQ; Marsh, Richards, Johnson, Roche, \& Tremayne, 1994). The ECP subscales for aggression and prosocial behaviours were utilized. These represent two of the five subscales that form the ECP. The other three subscales: shyness/withdrawal, popularity/sociability and victimization/exclusion, were removed from the measure. The items forming the aggression and prosocial subscales of the ECP reflect the constructs as they are currently viewed in the literature. For example, the subscale measuring general aggression includes items that reflect relational aggression in addition to items that reflect the more traditional physical and verbal forms of aggression (Burgess, et al., 2006). Furthermore, these subscales have adequate convergent validity when compared to teacher and parent ratings using the Child Behaviour Checklist and Parent- and Teacher-Child Rating Scales (Burgess, et al., 2006). The final 30 item ECP was found to have acceptable internal consistency across four different time periods with Cronbach alpha values ranging from .91 to .94 for aggression, and .82 to .89 for the prosocial subscale (Burgess, et al., 2006). Because the present study requested participants to think of liked and disliked peers, following the usual procedure for a class play type measure of nominating peers for each item was not possible, and the ECP was modified. The present study presented each item of the ECP as a five-point Likert scale with one indicating "Nothing like this person" and five indicating "Exactly like this person."

In addition to the ECP, participants were asked to rate liked and disliked peers on a measure of athletic ability. Items of this measure were modified from the Sport 
Behaviours of liked and disliked adolescents 19

Competence subscale of the PSDQ (Marsh, et al. 1994). The PSDQ has demonstrated good construct validity when compared to similar measures (Marsh, et al. 1994) and directly measuring the aspects intended by each subscale (Marsh, 1996).

The items from the Sport Competence subscale of the PSDQ were combined with the aggression and prosocial items from the ECP to form a single set of questions which used the same five-point Likert scale. This set of questions was responded to four times by each participant - once for each of four peers. Due to the combined items from two different questionnaires and the modified methodology of administering the questionnaires, internal consistency alpha coefficients were calculated using the results of the present study. The three subscales used in the present study provided good internal consistency. Cronbach alpha coefficients were calculated to be .92 for the aggression, .92 for the prosocial behaviour, and .96 for the athletic ability subscales.

Aggression, prosocial behaviour, and athletic ability as reported by each participant for the liked and disliked peers and gender of the participant as reported by parents were included in the main analyses. Demographic information and birth date were also collected from parents to check for the representativeness of the sample. Frequencies of ethnic backgrounds represented in the sample determined whether the results are generalizable to the general population or restricted to a certain set of ethnicities.

\section{Procedure}

Participants were recruited from sports and science/technology day camps at Carleton University, Ottawa area sports teams, and by networking through contacts formed with participants. Parents of potential participants were presented with an 
Behaviours of liked and disliked adolescents 20 informed consent form, and had the opportunity to ask any questions directly of the researcher. Although participants had the choice of internet-based or paper-and-pencil surveys, only three of the final sample of 122 opted to complete the survey in its paperand-pencil version.

As described earlier, each participant was asked to rate the aggressive, prosocial, and athletic competence behaviours of four recalled peers utilizing the appropriate subscales from the ECP (Burgess, et al., 2006) and PSDQ (Marsh, et al. 1994). The order in which participants were asked to think of each of the four peers and respond to the set of questionnaires for each peer was counterbalanced.

\section{Results}

The goal of the present study was to investigate the perceived aggression, prosocial behaviour, and athletic ability of early adolescents' liked and disliked peers from classroom and sports team settings. Potential differences between social status categories of liked and disliked peers, classroom and sports team social settings, and male and female participants were investigated. A sample of 12210 - to 13-year-olds rated the athletic ability, aggression and prosocial behaviour of four recalled peers, one liked and one disliked peer in a classroom and a sports setting. Differences in the behaviours were expected between social status categories of liked and disliked peers and between the setting categories of classrooms and sports teams. The social status and social setting variables were also expected to interact such that the perceptions of peers' behaviours that relate to social status depend upon the setting in which they occur. Finally, gender of the participants was also included in the main analyses to explore potential differences in the perceptions of male and female participants. 
Behaviours of liked and disliked adolescents 21

Prior to running the main analyses, data were screened for missing values and influential outliers. Participants were removed from the analyses if they had not responded to 25 percent or more of the peer ratings. Four participants from the original sample of 126 were removed for this reason. Two cases did not respond regarding peers in sports teams. One case did not respond regarding disliked peers, and one case did not respond regarding a disliked peer in a sports team. Missing data of the remaining 122 participants was minimal. Less than 0.36 percent of the ratings of peers' behaviour was missing. There appeared to be no pattern in these missing values in relationship to the ratings of athletic ability, aggression, prosocial behaviour, gender, ethnicity, age, and experience in sports. Cook's Distance and leverage were used to investigate possible influential outliers within the main analyses. None were found and all 122 participants were retained.

Athletic ability, aggression, and prosocial behaviour subscale scores measuring each participant's perception of liked classroom, liked sports, disliked classroom and disliked sports peers were calculated by taking the mean of the responses to the appropriate sets of descriptions. The athletic ability, aggression and prosocial behaviour scores were subjected to a three-way repeated measures MANOVA in which gender of the participant (male or female), setting (classroom or sports team setting) and social status (liked or disliked by members of the sports team or classroom) were the independent variables. Repeated measures analyses were appropriate since each participant reported the behaviours of four peers. Furthermore, a non-significant Box's $M$ $(F(78,44569)=1.03, p=.40)$ confirmed that the assumption of equal covariance matrices was met, and the main analysis could proceed. The results from the initial MANOVA are 
Behaviours of liked and disliked adolescents 22

displayed in Table 1. Significant results from the initial three-way repeated measures MANOVA were followed by univariate three-way repeated measures ANOVAs. The results of the follow-up univariate ANOVA for aggression are displayed in Table 2, for prosocial behaviour in Table 3 and for athletic ability in Table 4.

Table 1

Results of the MANOVA tests for all main effects and interactions effects.

\begin{tabular}{lccc}
\hline Source of Variability & Wilk's $\lambda$ & $F(3,118)$ & $p$-value \\
\hline Social Status & .18 & 180.96 & $<.001$ \\
Social Setting & .72 & 15.48 & $<.001$ \\
Gender & .94 & 2.63 & .05 \\
Status by Setting & .98 & .93 & .43 \\
Status by Gender & .98 & .67 & .57 \\
Setting by Gender & .97 & 1.09 & .36 \\
Status by Setting by & .94 & 2.62 & .05 \\
Gender & & & \\
\hline
\end{tabular}




\section{Table 2}

Behaviours of liked and disliked adolescents 23

Results of the ANOVA tests for all main effects and interaction effects on aggression.

\begin{tabular}{lccc}
\hline Source of Variability & $F(1,120)$ & $p$-value & partial $\eta^{2}$ \\
\hline Social Status & 146.65 & $<.001$ & .55 \\
Social Setting & 3.05 & .08 & .03 \\
Gender & 7.88 & .01 & .06 \\
Status by Setting & 1.02 & .31 & .01 \\
Status by Gender & 0.70 & .41 & .01 \\
Setting by Gender & 2.49 & .12 & .02 \\
Status by Setting by & 6.93 & .01 & .06 \\
Gender & & & \\
\hline
\end{tabular}


Table 3

Results of the ANOVA tests for all main effects and interaction effects on prosocial behaviour.

\begin{tabular}{lccc}
\hline Source of Variability & $F(1,120)$ & $p$-value & partial $\eta^{2}$ \\
\hline Social Status & 245.59 & $<.001$ & .67 \\
Social Setting & 4.57 & .04 & .04 \\
Gender & 2.74 & .10 & .02 \\
Status by Setting & 0.24 & .63 & $<.01$ \\
Status by Gender & 1.82 & .18 & .02 \\
Setting by Gender & 0.77 & .38 & .01 \\
Status by Setting by & 2.89 & .09 & .02 \\
Gender & & & \\
\hline
\end{tabular}


Table 4

Behaviours of liked and disliked adolescents 25

Results of the ANOVA tests for all main effects and interaction effects on athletic ability.

\begin{tabular}{lccc}
\hline Source of Variability & $F(1,120)$ & $p$-value & partial $\eta^{2}$ \\
\hline Social Status & 320.82 & $<.001$ & .73 \\
Social Setting & 37.70 & $<.001$ & .24 \\
Gender & 0.10 & .75 & $<.01$ \\
Status by Setting & 1.84 & .18 & .02 \\
Status by Gender & 0.22 & .64 & $<.01$ \\
Setting by Gender & 0.33 & .57 & $<.01$ \\
Status by Setting by & 0.98 & .32 & .01 \\
Gender & & &
\end{tabular}

The initial MANOVA compared the differences between the perceptions of liked and disliked peers, peers from classrooms and sports team settings, and reports of male and female peers on the set of dependent variables including perceived aggression, prosocial behaviour, and athletic ability of peers. The MANOVA revealed a significant main effect of status (Wilk's $\lambda=0.18, F(3,118)=180.96, p<.001$ ). Three follow-up univariate tests were used to determine on which of the dependent variables the liked and disliked peers were perceived to differ.

As displayed in Table 5, the main effect of status on athletic ability was significant and had the largest effect size $\left(F(1,120)=320.82, p<.001\right.$, partial $\left.\eta^{2}=.73\right)$. The effect of status on prosocial behaviour was also significant with a large effect size $\left(F(1,120)=245.59, p<.001\right.$, partial $\left.\eta^{2}=.67\right)$. As hypothesized, both athletic ability and prosocial behaviour were perceived to be greater among liked peers (prosocial $M=4.00$, 
Behaviours of liked and disliked adolescents 26 athletic ability $M=4.15$ ) than among disliked peers (prosocial $M=2.42$, athletic ability $M=2.47)$. Liked and disliked peers were also perceived to differ in levels of aggression as hypothesized $\left(F(1,120)=146.65, p<.001\right.$, partial $\left.\eta^{2}=.55\right)$. The disliked peers were perceived to be more aggressive $(M=3.21)$ than liked peers $(M=1.90)$. Table 5 Means and standard deviations of the three behaviours in each of the social status categories.

\begin{tabular}{lllll}
\hline & \multicolumn{2}{c}{ Liked Peers } & \multicolumn{2}{c}{ Disliked Peers } \\
\cline { 2 - 5 } & $M$ & $S D$ & $M$ & $S D$ \\
\hline Aggression & $1.90_{\mathrm{a}}$ & 0.91 & $3.21_{\mathrm{b}}$ & 1.05 \\
Prosocial & $4.00_{\mathrm{a}}$ & 0.76 & $2.42_{\mathrm{b}}$ & 0.92 \\
Athletic Ability & $4.15_{\mathrm{a}}$ & 0.75 & $2.47_{\mathrm{b}}$ & 1.10 \\
\hline
\end{tabular}

Note. Means in a row with different subscripts are significantly different $(p<.001)$.

These results all support the hypothesis that liked adolescents would be perceived to be less aggressive, more prosocial and have better athletic ability than disliked adolescents. Given the abundance of past research which suggested these hypotheses, the strength of these results is not surprising. However, these results are important since they confirm that the participants were able to follow the instructions to "think of someone you know in a classroom at school who was liked by lots of people in the class," and similar instructions for disliked peers and peers from sports teams. Participants were able to effectively remember peers within both settings who were liked and disliked and report their behaviours accurately. These results are important due to the unique method within 
Behaviours of liked and disliked adolescents 27 the present study, asking participants to retrospectively consider the behaviours of liked and disliked peers.

In addition to the main effect of social status, the initial MANOVA revealed a significant main effect of social setting (Wilk's $\lambda=0.72, F(3,118)=15.48, p<.001$ ). This result suggests that participants' perceptions of the set of behaviours - athletic ability, aggression and prosocial behaviour - of their peers differs between classrooms and sports settings. The means and standard deviations being compared in the univariate follow-up tests for the three behaviours are displayed in Table 6 . The main effect of setting in the MANOVA appeared mostly to be due to athletic ability. The univariate main effect of setting on athletic ability was significant $(F(1,120)=37.70, p<.001$, partial $\left.\eta^{2}=.24\right)$. Peers from sports settings were perceived to have greater athletic ability $(M=3.52)$ than peers from classroom settings $(M=3.09)$. Surprisingly, the multivariate main effect of setting was also due to a significant univariate effect of prosocial behaviour $\left(F(1,120)=4.57, p=.04\right.$, partial $\left.\eta^{2}=.04\right)$. Peers from a sports setting were perceived to display more prosocial behaviour $(M=3.27)$ than peers from a classroom setting $(M=3.15)$. This result contradicted the hypothesis that prosocial behaviour would not differ between settings. Also contrary to the present study's hypothesis, the univariate main effect of setting on aggression was not significant $(F(1,120)=3.05, p=.08$, partial $\eta^{2}=.03$ ). This result was marginally significant, but it was in the opposite direction than what was hypothesized. Despite research suggesting that at least physical aggression is viewed as more acceptable (Bredemeier, \& Shields, 1984) and frequent within athletes (Bredemeier, et al., 1986), participants in the present study tended to reported more aggression in classroom settings $(M=2.61)$ than in sports settings $(M=2.49)$. 
Table 6

Behaviours of liked and disliked adolescents 28

Means and standard deviations of the three behaviours in each of the social setting categories.

\begin{tabular}{lcccc}
\hline & \multicolumn{2}{l}{ Classroom setting } & \multicolumn{2}{l}{ Sports setting } \\
\cline { 2 - 5 } & $M$ & $S D$ & $M$ & $S D$ \\
\hline Aggression & 2.61 & 1.20 & 2.49 & 1.15 \\
Prosocial & $3.15_{\mathrm{a}}$ & 1.16 & $3.27_{\mathrm{b}}$ & 1.13 \\
Athletic Ability & $3.09_{\mathrm{a}}$ & 1.32 & $3.52_{\mathrm{b}}$ & 1.17 \\
\hline
\end{tabular}

Note. Means in a row with different subscripts are significantly different $(\mathrm{p}<.05)$.

The third main effect of the initial repeated measures MANOVA compared male and female participants' mean ratings on the set of behaviours. The mean levels of aggression, prosocial behaviour and athletic ability as perceived by male participants and by female participants are displayed in Table 7 . The main effect of gender of the participants in the MANOVA was significant (Wilk's $\lambda=.94, F(3,118)=2.63, p=.05)$. This effect was due to the significant univariate effect of gender of the participants on $\operatorname{aggression}(F(1,120)=7.88, p=.006)$, partial $\left.\eta^{2}=.06\right)$. Within this difference, male participants reported more aggression $(M=2.67)$ than female participants $(M=2.42)$. This result was expected from past research suggesting that physical aggression and threats of physical aggression are more common among boys than girls (see Maccoby, 1990). The univariate main effects of gender of the participants on prosocial behaviour and athletic ability were not significant indicating that male and female participants did not differ in their perceptions of the levels of prosocial behaviour and athletic ability displayed by their peers. 
Table 7

Behaviours of liked and disliked adolescents 29

Means and standard deviations of the three behaviours as perceived by male and female participants.

\begin{tabular}{lcccc}
\hline & \multicolumn{2}{l}{ Male Participants } & \multicolumn{2}{l}{ Female Participants } \\
\cline { 2 - 5 } & $M$ & $S D$ & $M$ & $S D$ \\
\hline Aggression & $2.67_{\mathrm{a}}$ & 1.19 & $2.42_{\mathrm{b}}$ & 1.15 \\
Prosocial & 3.15 & 1.09 & 3.27 & 1.21 \\
Athletic Ability & 3.32 & 1.25 & 3.29 & 1.28 \\
\hline
\end{tabular}

Note. Means in a row with different subscripts are significantly different $(p<.01)$.

Following the analyses of main effects, pairwise interactions were investigated.

The results displayed in Table 1 illustrate that none of the pairwise interactions among gender, social setting and social status were significant in the initial MANOVA. Thus, the main effects discussed above did not differ depending upon the level of one of the other variables - status, setting or gender. Of particular interest was that the setting by status interaction was not significant (Wilk's $\lambda=.98, F(3,118)=0.93, p=.43$ ). This result refutes the hypothesis that the relationships between the behaviours (aggression, prosocial and athletic ability) and social status (liked or disliked peers) would depend upon the type of social setting (classrooms or sports teams).

However, the three-way, gender by social status by social setting interaction from the initial three-way repeated measures MANOVA was significant (Wilk's $\lambda=.94$, $F(3,118)=2.62, p=.05)$. This interaction effect was significant only for the setting by status by gender univariate ANOVA on aggression $\left(F(1,120)=6.93, p=.01\right.$, partial $\eta^{2}=$ $.06)$. Thus, the differences in the mean perceptions of liked and disliked peers' aggressive 
Behaviours of liked and disliked adolescents 30 behaviour depended upon the combination of the levels of gender and social setting. To investigate this interaction, separate social status by social setting repeated measures ANOVAs on aggression were run for males and females.

The resulting interaction plots displaying the perceptions of male and female participants from these social setting by social status ANOVA analyses are presented in Figure 1. Male participants' perceptions of peers' aggression are displayed in the left hand interaction plot, and female participants' perceptions of peers' aggression are displayed in the right hand interaction plot. Examining these plots, one can easily detect the significant main effect of social status on aggression mentioned earlier. The simple effects of social status at each combination of the levels of social setting and gender reflect the main effect that disliked peers were perceived to be more aggressive than liked peers. By examining how the simple effects of social status on perceptions of aggression at each level of social setting are different between male and female participants, and how the simple effects of social setting on perceptions of aggression at each level of social status differ between male and female participants, the contributions to the threeway interaction can be revealed.

Comparing the plots in Figure 1, it is apparent that females perceived the aggressive behaviour of liked and disliked peers within classrooms to differ to a greater extent than male participants. This apparent difference between male and female participants in the simple effects of status at the classroom level of setting was significant $(t(120)=2.03, p=.04)$. Since the classroom setting is typically mixed-sex, this result suggests that male and female participants perceive similar settings to differ. Apparently, females perceive aggression as more unacceptable in classrooms than male participants. 
Behaviours of liked and disliked adolescents 31 Male and female participants did not differ in their perceptions of the difference between liked and disliked peers in sports settings $(t(120)=0.95, p=.35)$.

One other comparison between male and female participants contributed to the three-way interaction. Examining the interaction plot on the right hand side of Figure 1, one will notice that female participants perceived the aggressive behaviour of disliked peers to be greater in a classroom setting than in a sports setting $(t(57)=2.43, p=.02)$. Although the same simple effect was not significant for male participants $(t(63)=-1.75, p$ $=.09)$, the trend was in the opposite direction than for female participants. Male participants tended to perceive the aggression of disliked peers in a classroom setting to be less than a sports setting. This resulted in a significant difference between male and female participants regarding the simple effect of setting on perceptions of aggression for disliked peers $(t(120)=2.94, p=.004)$. Comparing male and female participants on the other simple effects of social status and social setting on aggression did not produce significant results. 


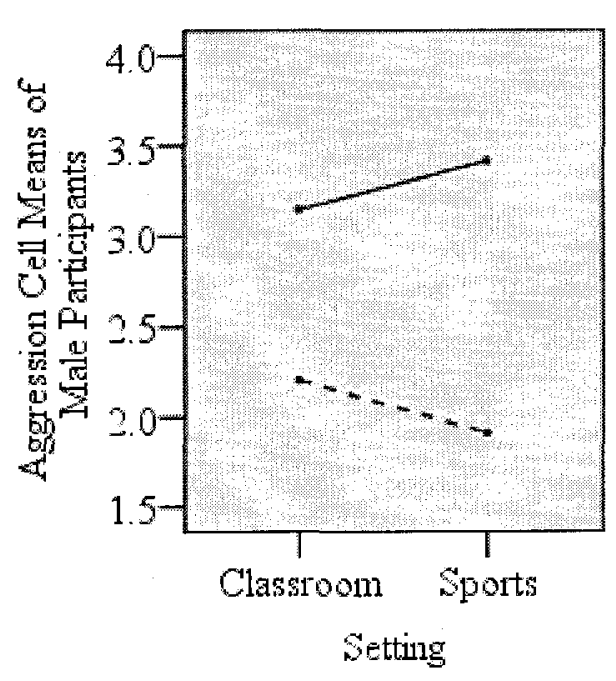

Behaviours of liked and disliked adolescents 32

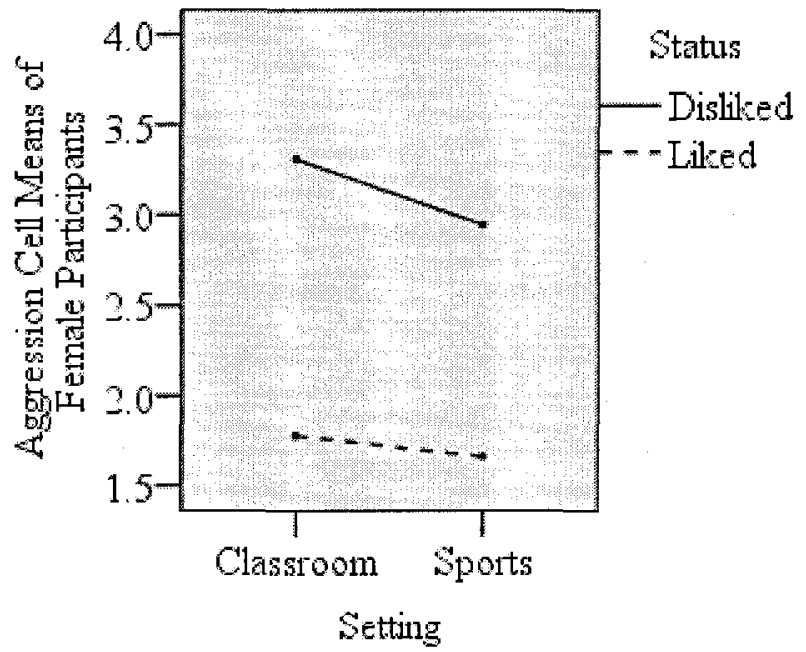

Figure 1. Social status by social setting interaction plots displaying cell means of aggression as perceived by male and female participants.

Furthermore, the setting by status interaction for male participants displayed in Figure 1 was significant $\left(F(1,63)=6.20, p=.02\right.$, partial $\left.\eta^{2}=.09\right)$, but it was not significant for females $\left(F(1,57)=1.46, p=.23\right.$, partial $\left.\eta^{2}=.03\right)$. Examining the portion of Figure 1 that displays the significant setting by status interaction for male participants, one will notice that the difference in the perceived aggression between liked and disliked peers is significantly greater in the sports setting than in classroom settings $(t(126)=$ $2.10, p=.04)$. This same difference for female participants was not significant $(t(114)=$ $.952, p=.34)$.

Thus, the three-way interaction is attributable to female participants perceiving the aggression of disliked peers to be greater in classrooms than sports settings while male participants tended to perceive disliked peers in classrooms to behave less aggressively than in sports settings. Secondly, the three-way interaction is attributable to females perceiving the difference between the aggression of liked and disliked peers in 
Behaviours of liked and disliked adolescents 33 classroom settings to be greater than male participants. Finally, the social setting by status interaction for male participants indicated a greater difference between perceptions of aggression of liked and disliked peers in sports than in classrooms while the social setting by status interaction on aggression for female participants was not significant.

Examining these results more carefully, the result for male participants contradicts the original hypothesis. Due to past research which suggests that athletes are more accepting of physical aggression (Bredemeier, \& Shields, 1984) and that generally aggression is less related to being disliked in highly aggressive groups (Wright, et al., 1986; Boivin, et al., 1995; and Stormshack, et al., 1999), it was expected that perceptions of aggression would not distinguish liked and disliked peers in sports team social settings. However, the above significant setting by status interaction for male participants shows the opposite; perceptions of aggression distinguished liked and disliked peers to a greater extent in sports teams than classroom settings for male participants.

One possible reason for these contradictory results is that some of the types of aggression included in the ECP are undesirable in sports teams. Physical aggression may be advantageous in many sports since it can easily be directed to opponents and contribute to a competitive advantage. Physical aggression would be expected to conform to the original hypothesis and not distinguish liked from disliked peers in sports teams because both aggressive and non-aggressive peers may be liked or disliked. On the other hand, relational aggression is unlikely to be directed toward the opposition and unlikely to contribute to the goals of a sports team. Instead, relational aggression may undermine the efforts to build a cohesive and cooperative team. Displays of relational aggression in a sports team may be particularly aversive to team members. Consequently, those who 
Behaviours of liked and disliked adolescents 34 display relational aggression may be more likely to be disliked than liked. To explore this potential explanation, social status by social setting by gender repeated measures ANOVAs were conducted for responses to the physical aggression item "A person who gets into a lot of fights," and for responses to the relational aggression item from the ECP, "Someone who spreads rumours about other kids so that people won't like them anymore." The results of the tests on the perceptions of peers' physical aggression are displayed in Table 8, and the results of the tests on the perceptions of peers' relational aggression are displayed in Table 9.

Table 8

Results of the ANOVA tests for all main effects and interaction effects on physical aggression.

\begin{tabular}{lccc}
\hline Source of Variability & $F(1,120)$ & $p$ & partial $\eta^{2}$ \\
\hline Social Status & 134.55 & $<.001$ & .53 \\
Social Setting & 5.47 & .02 & .04 \\
Gender & 4.91 & .03 & .04 \\
Status by Setting & 0.49 & .49 & $<.01$ \\
Status by Gender & 1.68 & .20 & .01 \\
Setting by Gender & 2.46 & .12 & .02 \\
Status by Setting by & 4.47 & .04 & .04 \\
Gender & & & \\
\hline
\end{tabular}


Table 9

Behaviours of liked and disliked adolescents 35

Results of the ANOVA tests for all main effects and interaction effects on relational aggression.

\begin{tabular}{lccc}
\hline Source of Variability & $F(1,120)$ & $p$ & partial $\eta^{2}$ \\
\hline Social Status & 69.70 & $<.001$ & .37 \\
Social Setting & 0.01 & .93 & $<.01$ \\
Gender & 2.38 & .13 & .02 \\
Status by Setting & 4.70 & .03 & .04 \\
Status by Gender & 0.01 & .95 & $<.01$ \\
Setting by Gender & 0.82 & .37 & .01 \\
Status by Setting by & 0.26 & .61 & $<.01$ \\
Gender & & &
\end{tabular}

For both physical and relational aggression, the main effect of social status was significant $\left(F(1,120)=134.55, p<.001\right.$, partial $\eta^{2}=.53$, and $F(1,120)=69.70, p<.001$, partial $\eta^{2}=.37$, respectively). As expected, disliked peers were perceived to be more physically and more relationally aggressive than liked peers. The main effect of social setting on physical aggression was also significant $\left(F(1,120)=5.47, p=.02\right.$, partial $\eta^{2}=$ .04). However, this result contradicted expectations; peers from sports teams were perceived to be less physically aggressive than peers from classrooms. Peers from classrooms and sports teams were not perceived to differ on relational aggression $\left(F(1,120)=.01, p=.93\right.$, partial $\left.\eta^{2}<.01\right)$. The main effect of gender on relational aggression was not significant $\left(F(1,120)=2.38, p=.13\right.$, partial $\left.\eta^{2}=.02\right)$, but it was significant for physical aggression $\left(F(1,120)=4.91, p=.03\right.$, partial $\left.\eta^{2}=.04\right)$. Male 
Behaviours of liked and disliked adolescents 36 participants $(M=2.84)$ reported peers to be more physically aggressive than female participants $(M=2.47)$.

The setting by status interaction was significant for relational aggression $\left(F(1,120)=4.70, p=.03\right.$, partial $\left.\eta^{2}=.04\right)$. As displayed in Figure 2, this interaction was due to the greater difference between the perceived relational aggression of disliked peers and liked peers within sports team social settings than classroom settings. This result follows the reasoning stated above. Relational aggression appears to be more aversive in sports teams than classrooms and thus disliked and liked peers are perceived to be more different in relational aggression in a sports setting than a classroom setting. This result did not differ between male and female participants since the setting by status by gender interaction effect on relational aggression was not significant $(F(1,120)=0.26, p=.61$, partial $\left.\eta^{2}<.01\right)$ 
Behaviours of liked and disliked adolescents 37

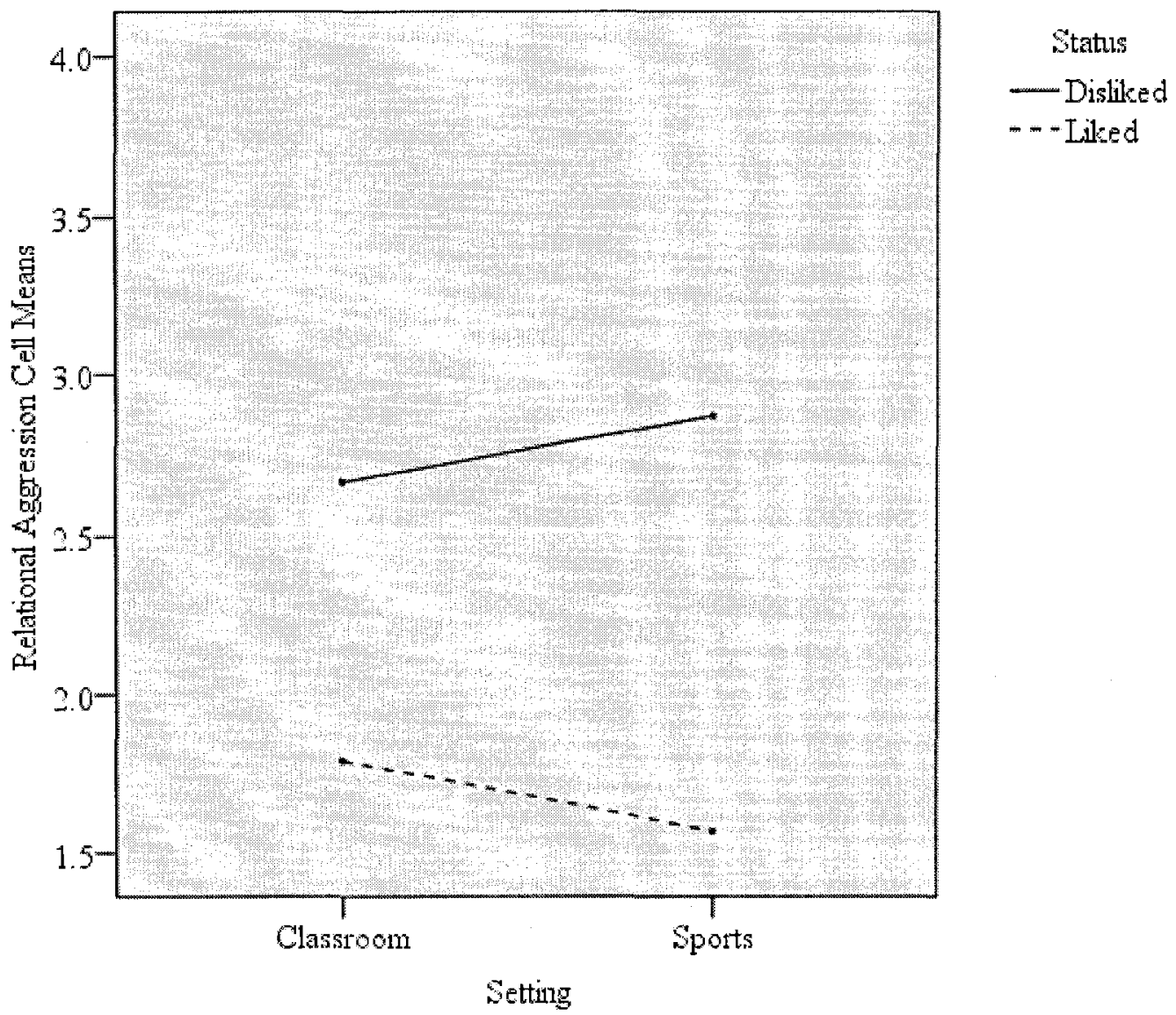

Figure 2. Social status by social setting interaction plot displaying cell means of relational aggression.

The setting by status by gender interaction effect on participants' perceptions of physical aggression was significant $\left(F(1,120)=4.47, p=.01\right.$, partial $\left.\eta^{2}=.04\right)$. Separate social status by social setting ANOVAs for male and female participants were conducted to investigate this interaction. The differences between the status by setting interaction effects on physical aggression between male and female participants accounted for the significant setting by status by gender interaction for physical aggression.

First of all, the setting by status interaction effect on physical aggression for peers reported by female participants displayed in the right hand interaction plot of Figure 3 
Behaviours of liked and disliked adolescents 38 approached significance $\left(F(1,57)=3.82, p=.06\right.$, partial $\left.\eta^{2}=.06\right)$. The same interaction for male participants displayed in the left hand interaction plot of Figure 3 was not significant $\left(F(1,63)=1.04, p=.31\right.$, partial $\left.\eta^{2}=.02\right)$. However, these interaction plots do differ in their directions. Two differences between perceptions of male and female participants accounted for the setting by status by gender interaction on physical aggression. Although both male and female participants generally perceived disliked peers to display more physical aggression than liked peers, male and female participants appeared to differ in their perceptions of how this behaviour relates to social status when classrooms are compared to sports teams. Male participants perceived the physical aggression of liked and disliked peers in classrooms to be more similar than female participants $(t(120)=2.16, p=.03)$. Applying the person-group similarity hypothesis and the self categorization theory, this result suggests that female adolescents respond to physical aggression of peers in classrooms more negatively than male adolescents. Males and females perceived the difference between the physical aggression of liked and disliked peers in sports teams more similarly $(t(120)=0.49, p=.63)$.

The second difference which contributed to the three-way interaction on physical aggression involved disliked peers. The simple effect of setting on physical aggression for disliked peers as perceived by male participants was not significant $(t(63)=.078, p=$ .73), but it was significant for female participants $(t(57)=2.82, p=.01)$. Female participants perceived disliked peers in sports teams $(M=2.91)$ to be less physically aggressive than classrooms $(M=3.62)$, as can be seen in Figure 3. The difference between male and female participants in their simple effects of setting on physical aggression for disliked peers was significant $(t(120)=2.34, p=.02)$. 
Behaviours of liked and disliked adolescents 39
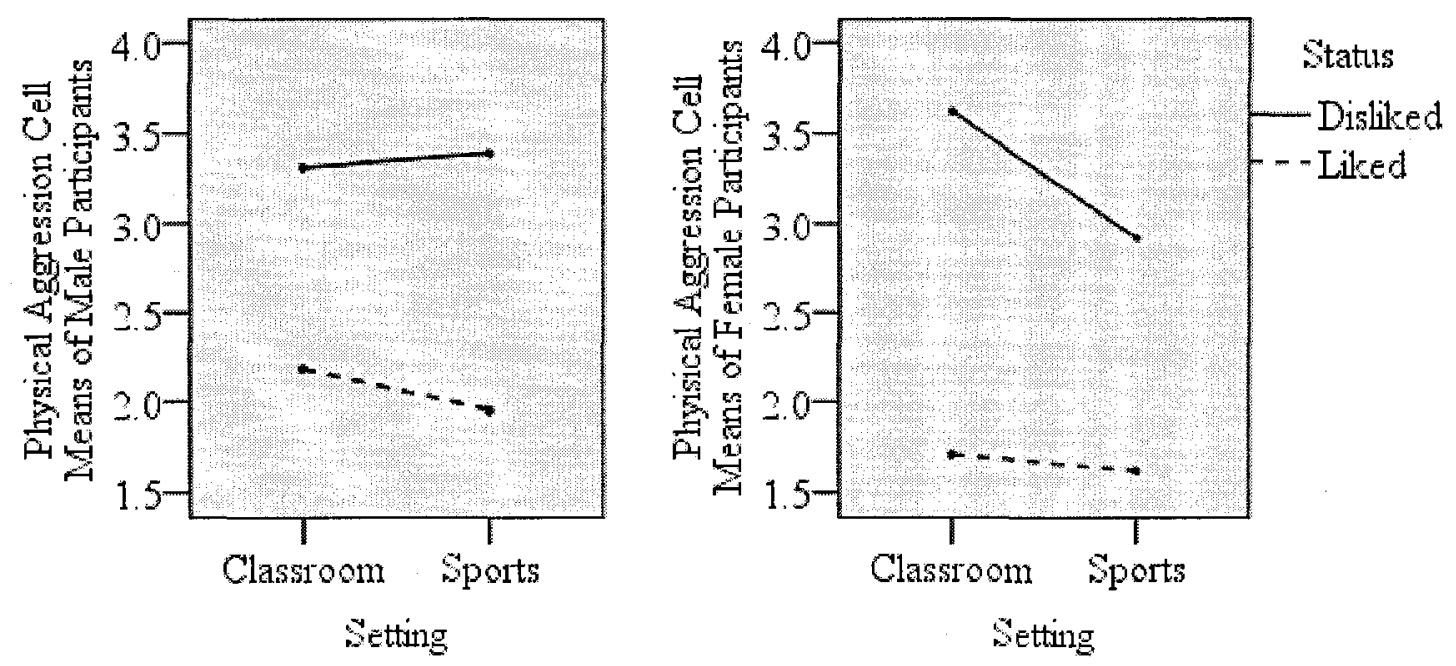

Figure 3. Social status by social setting interaction plots displaying cell means of physical aggression as perceived by male and female participants.

These results illustrate the importance of considering different types of aggression as they relate to adolescents' social status. The results above indicate that physical and relational aggression relate to social status differently. The relationships between social status and aggression differ depending upon the type of aggression, the social setting and the gender of the group members. 
Behaviours of liked and disliked adolescents 40 Discussion

The present study aimed to investigate the perceived behaviours of liked and disliked adolescents while taking into consideration possible differences between classroom and sports team social settings and participants' gender. Participants responded to surveys requesting their perceptions of aggression, prosocial behaviour and athletic ability of four peers - a liked and a disliked peer in a classroom setting and a liked and a disliked peer in a sports team setting. This data was used to meet three objectives within the broader purpose of this study. The first objective was to compare the perceived behaviours of liked peers to those of disliked peers. Past research suggested the hypotheses that liked peers would be perceived to be more prosocial and athletic and less aggressive than disliked peers. The second objective was to compare the perceptions of behaviours in classrooms and sports teams. Of particular interest were possible differences in the behaviours liked and disliked peers were perceived to display depending upon the type of social setting. The third objective was to explore gender differences in perceptions of peers. The present study offered a unique opportunity to explore gender differences, since classrooms are generally of mixed sexes and sports teams are generally sex segregated. These three objectives were met, and the hypotheses of all three objectives were at least partially supported.

\section{Behaviours of Liked and Disliked Peers}

The hypotheses that liked peers would be perceived to be more prosocial and athletic, and less aggressive than disliked peers was guided by an abundance of research. For all three behaviours, hypotheses were confirmed in the present study. Liked peers were perceived to display higher levels of prosocial behaviour and athletic ability than 
Behaviours of liked and disliked adolescents 41 disliked peers, and disliked peers were perceived to display higher levels of aggression than liked peers. Results confirmed past research. In particular the meta-analysis by Newcomb and colleagues (1993) concluded this pattern of behaviours for liked and disliked peers.

The present study not only offers further support for this finding, but also contributes to the robustness of these results since an unconventional method was used. The most frequently used method to explore the behaviours of liked and disliked children has been to collect nominations from groups of children. The peer nomination methods designed by Coie and colleagues (1982) and Newcomb and Bukowski (1984) are among the most widely used. Key methodological differences between the present study and the more conventional method of Coie and his colleagues (1982) included using ratings of behaviours of liked and disliked peers as opposed to nominations of peers' behaviours, having participants think of peers who were liked and disliked by a group rather than using standardized scores calculated from participants' own liked most and liked least nominations from the entire group. Despite several methodological differences, the results that liked peers were perceived to be more prosocial and athletic, and less aggressive than disliked peers reflect the majority of past research.

Furthermore, the results of the present study indicated that the differences in the behaviours of liked and disliked peers were perceived to be large. Effect sizes ranged from partial $\eta^{2}$ values of .55 for aggression to .73 for athletic ability. These values can be interpreted as the proportion of explained variability, and values larger than .25 can be considered large (Tabachnick \& Fidell, 2007). Thus, a proportion of .55 of the variability in perceived aggression of peers was attributable to their social status categories, either 
Behaviours of liked and disliked adolescents 42

liked or disliked. Similarly, proportions of .67 and .73 of the variability in perceptions of peers' prosocial behaviour and athletic ability, respectively, were associated with social status. Of the three variables included in the present study, social status, social setting and gender, peers' behaviours were perceived to be most associated with whether a child was liked or disliked.

\section{Comparing Classrooms and Sports Teams}

The results that liked and disliked children were perceived to behave differently were both statistically reliable ( $p$-values for aggression, prosocial behaviour and athletic ability were all less than .001) and of practical significance (effect sizes were large with partial $\eta^{2}$ values of .55 and greater). However, Maccoby (1990) suggested that to completely understand social phenomena, researchers must include more than individual factors alone. The second objective of the present study aimed to accomplish this by comparing the behaviours participants reported liked and disliked peers to display in classrooms to sports teams. Of particular importance was the hypothesis predicting a social status by social setting interaction effect on the behaviours.

The multivariate social status by social setting interaction was not significant, indicating that the pattern of the relationships between social status and aggression, prosocial behaviour and athletic ability did not differ depending on the social setting categories of classrooms and sports teams. For both classrooms and sports teams, adolescents who are prosocial, athletic and not aggressive are most likely to be well liked by their peers. However, the significant main effect of social setting and significant social setting by status by gender interaction for aggression support the importance of studying different social contexts in peer relations research. 
Behaviours of liked and disliked adolescents 43

Social status and social setting were hypothesized to interact for aggression due to the person group similarity hypothesis, the self categorization hypothesis, and past research. The difference between perceptions of liked and disliked peers' aggression was expected to be greater in classrooms than sports teams. Aggression was expected to be perceived as more common and more accepted in sports teams (see Bredemeier, \& Shields, 1984; and Bredemeier, et al., 1986). The person-group similarity hypothesis would suggest that aggression would not be as strongly related to being liked and disliked by peers in a highly aggressive setting (Wright et al., 1986; Boivin et al., 1995;

Stormshak et al., 1999). Also, the self-categorization theory suggests that people who behave in accordance with the norms of the group are candidates for inclusion while those whose behaviour does not fit the group are likely to be excluded (Parkinson, et al., 2005). Furthermore, groups emphasize the similarities of group members and differences of non-members (Parkinson, et al., 2005). These points supported the hypothesis that participants would perceive liked and disliked peers to be similar in their aggression scores more frequently in sports settings than classroom settings.

Similarly, social status and social setting were expected to interact for athletic ability. Athletic ability was expected to differentiate perceptions of liked and disliked peers more in sports teams than classrooms due to its value to sports teams accomplishing their goals. Again the self-categorization theory is applicable. Athletic adolescents will be able to help their sports teams accomplish their goals. The self-categorization theory would suggest these people would be included (Parkinson, et al., 2005). Those who are not athletically skilled will be less able to contribute to the team's goals and be excluded. Because athletic ability was expected to be less important in classrooms compared to 
Behaviours of liked and disliked adolescents 44 sports teams, liked and disliked peers were expected to be perceived to be more similar in their athletic ability in classrooms compared to sports teams.

Finally, the social status by social setting interaction was not expected for prosocial behaviour. The differences between liked and disliked peers' prosocial behaviour was expected to be approximately equal for sports teams and classrooms. This follows from past research concluding that prosocial behaviour to be valued equally across social groups (Stormshak, et al., 1999; Boivin, et al., 1995).

Despite the expectations that social status and social setting would interact for aggression and athletic ability, the interaction was not significant for any of the behaviours. This result suggests that the behaviours that relate to social status among adolescent peers are generally the same across groups. Despite the person-group similarity hypothesis, the self categorization theory, and the reasons to believe that children in classrooms and sports teams should differ in their responses to aggression and athletic ability, the children high in athletic ability and prosocial behaviour and low in aggression are likely to be the most liked in both settings. Those low in athletic ability and prosocial behaviour and highly aggressive are likely to be the most disliked in both settings. The social setting appears to have little relationship to the behaviours perceived to be displayed by liked and disliked peers.

However, the significant main effect of social setting on prosocial behaviour and athletic ability and approaching significance on aggression support the importance of considering social factors when investigating peer relations. Although the behaviours liked and disliked adolescents are perceived by their peers display follow the same pattern in classrooms and sports teams, these settings differ in other important ways. 
Behaviours of liked and disliked adolescents 45

Results indicated that peers were perceived to display more prosocial and have higher athletic ability in sports teams than in classrooms. Peers tended to be perceived as less aggressive in sports settings than in classroom settings, although this effect only approached significance.

Adolescents who are prosocial, athletic and not aggressive are most likely to be liked, and adolescents who are not prosocial or athletic, but are aggressive are most likely to be disliked in both classrooms and sports settings. However, the result that peers from sports teams were perceived to be more prosocial and athletic, and tended to be less aggressive than classrooms suggests that experiences with peers likely differ between classrooms and sports teams. Perhaps sports teams may be a more positive setting if an individual is reasonably athletically competent. Children who are the most disliked individuals in their classrooms are likely to also be the most disliked in sports teams, but with the higher levels of prosocial behaviour and possibly lower levels of aggression, these children may perceive the sports setting to be more welcoming. An alternative possibility is that children who are disliked in classrooms simply do not play sports. The ones who do play sports may be of an average to liked status with corresponding average to high levels of prosocial behaviour and athletic ability in classrooms. These adolescents may find themselves at the lower end of both behaviours and consequently more likely to be disliked in a sports team. Individuals who have found themselves to be of an average social status at school may find themselves among the most disliked in a sports team.

The higher prosocial behaviour perceived in peers from sports teams than classrooms suggests another possible benefit of participation in sports. Athletes may benefit from participating in a group which tends to frequently display prosocial 
Behaviours of liked and disliked adolescents 46 behaviour. Being exposed to peers who model prosocial behaviour may help them to learn to be more prosocial across social settings. This may be particularly effective for adolescents who are receiving an intervention to help them to improve their prosocial behaviour. Seeing peers behaving prosocially may provide added benefit to receiving the message to be more prosocial through, for example, coaching strategies.

Furthermore, the results of the present study have demonstrated that members of sports teams are perceived to have greater athletic ability than the more general classroom setting. This suggests that early adolescents are self-selecting based upon their athletic ability and perhaps their shared interest and value placed on this ability. While many classrooms and schools expose students to a great variety of peers with differing abilities, ethnicities, interests and values, sports and other extracurricular activities likely offer more homogeneous social settings in which members can meet peers with similar interests, abilities and values. Belonging to a relatively homogeneous group may help members to develop a sense of belonging which according to Baumeister and Leary (1995) is among the most fundamental human needs.

These results suggest several possible ways sports participation may benefit adolescents' peer relations. The experiences with peers in sports teams may be more positive than in classrooms. Sports teams may help adolescents develop prosocial behaviour through peer modeling. Sports teams may also be more homogeneous, helping young athletes to develop a sense of belonging. These possibilities should be tested against the alternative possibility that children of an average status in classrooms may find themselves lacking prosocial behaviour and athletic ability compared to peers in a 
Behaviours of liked and disliked adolescents 47

sports team setting, and thus may feel that their experience relating to peers has become more negative.

\section{Gender Differences}

The main effects that classrooms and sports teams differ in the perceived levels of prosocial behaviour and athletic ability support the objective to investigate the possible role of social factors in peer relations research even though the hypothesis that social setting and status would interact was not confirmed. The present study's purpose was supported further by exploring possible differences between male and female participants - the third and final objective. The main effect of gender on aggression and the social status by social setting by gender interaction were both significant for aggression suggesting important differences in the ways male and female participants respond to aggressive peers.

Differences between males and females should not be surprising, particularly when investigating social phenomena (Maccoby, 1990). For the purposes of the present study, the term 'gender' was chosen over the term 'sex' to emphasize the differences between male and female perceptions of behaviours that relate to social interaction. Psychological researchers have been encouraged to use gender when discussing sociocultural differences between males and females, particularly differences between what is considered appropriate for males and females, and to use sex when referring to biological mechanisms (Unger, 1979).

Social experiences of late childhood and early adolescence may differ between males and females due in part to preferences to engage in play with members of one's own gender. Preferences to play with same-sex peers occur in high levels until at least 11 
Behaviours of liked and disliked adolescents 48 years old (Maccoby, 1990). Within these frequently gender-segregated groups, girls tend to emphasize interpersonal relationships and use enabling styles of interaction. Boys tend to organize their groups according to dominance hierarchies and use restrictive interaction patterns (Maccoby, 1990).

The main effect of gender on aggression confirmed the hypothesis that male participants would perceive more aggression in their peers than female participants. Male participants may have been both more willing to report aggression and their peers may have been more aggressive than female participants. This suggests that male and female participants differed in the way they respond to aggression. Given the frequent inclusion of aggression, toughness, violence and daring among gender norms for males, and the focus on openness, caring and beauty typical of female gender norms and stereotypes (Doyle \& Paludi, 1998), gender differences regarding aggression were expected.

Within the developmental literature, results of studies testing the person-group similarity hypothesis have found that groups with lower levels of aggression are more likely to respond to aggressive behaviour by rejecting the individual (Wright, et al., 1986; Boivin, et al., 1995; Stormshak, et al., 1999). If the perceptions of male participants' peers were accurate and in reality more aggressive, this would suggest that the peer groups of male participants would generally be more accepting of aggression than the peer groups of female participants.

The setting by status by gender interaction adds further support that male and female participants perceive aggression differently. It also supports the proposal that social factors should be considered in peer relations research. To investigate the interaction, separate social status by social setting ANOVAs on aggression for male and 
Behaviours of liked and disliked adolescents 49 female participants were conducted. Figure 1 displays the results from these ANOVAs. Two main differences between male and female participants accounted for the three-way interaction. First female participants perceived the difference in aggression between liked and disliked peers in classrooms to be greater than for male participants. This result suggests that female participants respond to aggression in classrooms more strongly than male participants. Applying the self categorization theory (Parkinson, et al., 2005) to this result, aggression appears to be a behaviour that females use to define the acceptable behaviour of their peers in classrooms. Those who display aggression become candidates for exclusion. Peers who conform to the group norms by avoiding aggressive behaviour are more likely to be liked by the group. Female participants may also hold biased judgements and may emphasize the aggressive behaviour of disliked peers and the lack of aggressive behaviour of liked peers in classrooms (see Koslin, et al., 1968 and Parkinson, et al., 2005).

Male participants' perceptions on the other hand, indicate that males do not as consistently select aggressive peers for exclusion in classrooms. Male participants were more likely than female participants to rate disliked peers and liked peers as similar in their aggressive behaviour. Aggression may have less emphasis as an important behaviour for group membership as perceived by male participants compared to females.

The second difference between male and female participants which accounted for the three-way interaction was that the female participants perceived disliked peers from classrooms to be significantly more aggressive than sports teams while male participants tended to perceive disliked peers from classrooms to be less aggressive than sports teams. Again, this suggests that females may be more likely to dislike an aggressive peer in a 
Behaviours of liked and disliked adolescents 50 classroom than in a sports team. Females appeared more likely to exclude aggressive peers in classrooms than sports teams while male participants appeared more likely to exclude aggressive peers in sports teams than classrooms.

\section{A Closer Look at Aggression}

Together the main effect of gender and the three-way interaction on aggression support the importance of investigating the roles of both gender and social setting in peer relations research. However, the support from the analysis of the three-way interaction on aggression did not always follow the hypothesized differences. In particular, the social status by social setting interaction effect on aggression reported by male participants displayed in Figure 1 was significant, but in the opposite direction from what was hypothesized. Instead of liked and disliked peers being perceived to be more similar in their aggression in sports teams than classrooms, they were perceived to be more divergent in sports teams than in classrooms. This suggests that for males' sports teams the types of aggression measured by this study are more unacceptable than in classrooms. This puzzling result required a closer look at aggression as it was measured in this study.

The contradiction between the hypothesized social status by social setting interaction and the resulting interaction for male participants may be due to the types of aggression included in the ECP. The ECP was designed to contain a variety of types of aggression including physical, verbal and relational (Burgess, et al., 2006). While physical aggression may contribute to the goals of sports teams when it is directed at the opposition, the other items included in the ECP seem difficult to effectively direct at one's opposition. The majority of aggression items in the ECP may interfere with teams' 
Behaviours of liked and disliked adolescents 51

goals of developing teamwork and winning competitions. Sports teams would be likely

to value avoidance of aggression as measure by the ECP.

To test this possibility, separate social status by social setting by gender ANOVAs were conducted for the items of the ECP which were clearly physical aggression and clearly relational aggression. Because the other items could have been more than one type of aggression, this additional analysis was restricted to the items which were clearly physical aggression and clearly relational aggression.

As expected, relational aggression appeared to be more aversive in sports teams than in classrooms. This was indicated by a significant social setting by social status interaction. Participants perceived the difference between liked and disliked peers from sports teams to be greater than the difference between liked and disliked peers from classrooms. According to Parkinson and colleagues' (2005) interpretation of the self categorization theory, behaviours shared by group members and behaviours that differentiate group members from non-members are emphasized. Furthermore, group members behave in ways that contribute to the goals and conform to the values of the group (Parkinson, et al., 2005). In the present study, liked peers are likely central to the groups and conform to the normative behaviours of groups while disliked peers are likely on the verge of being excluded and likely behave in ways that contradict group values and interfere with their goals. Adolescents playing sports are motivated by winning competitions, having fun, and developing new friendships (Murphy, 1999; Hacker, 2005). The greater difference perceived between liked and disliked peers' relational aggression in sports teams than classrooms was expected because relational aggression likely interferes with the goals of sports teams to a greater extent than in classrooms. 
Behaviours of liked and disliked adolescents 52

Results concerning physical aggression were more complicated than those of

relational aggression. A three-way, gender by setting by status interaction effect on physical aggression suggested that the relationship between social status and physical aggression depends upon the specific combination of gender and social setting. Two significant simple effects contributed to the three-way interaction.

First, male and female participants differed in their perceptions of liked and disliked peers from classroom settings. Male participants perceived liked and disliked peers in classrooms to display levels of physical aggression that were more similar than female participants. The greater similarity between liked and disliked peers in classrooms as perceived by male participants compared to female participants suggests that physical aggression does not differentiate liked from disliked peers as strongly for male participants. This result would have been predicted by the person-group similarity hypothesis. The greater similarity between liked and disliked peers as perceived by male participants compared to female participants parallels research concluding that aggression becomes less related to social status as the level of aggression within the group increases (Wright, et al., 1986; Boivin, et al., 1995; Stormshak, et al., 1999; Chang, 2005). Past research concluding that males are more physically aggressive than females (Broidy, et al., 2003) agree with the results within the present study. Peers of male participants have higher levels of physical aggression as a group, and consequently it would be less likely to be an important behaviour in differentiating between liked and disliked adolescents.

This result also would have been predicted by the self-categorization theory. Just as relational aggression would have been expected to be more harmful to the goals of a sports team than a classroom, physical aggression may conflict with the normative 
Behaviours of liked and disliked adolescents 53 behaviour of female peer groups more than male peer groups, and thus be more likely to differentiate liked and disliked peers for females than males.

Second, male and female participants differed in their perceptions of disliked peers. While male participants perceived disliked peers in classrooms and sports teams to display approximately equal levels of physical aggression, female participants perceived disliked peers in sports teams to display significantly less physical aggression than in classrooms. This result contributed to a setting by status interaction on physical aggression as perceived by female participants displayed in Figure 3 which approached significance. Liked and disliked peers tended to be perceived to display more similar levels of physical aggression in sports teams compared to classrooms. This result for female participants supports the initial hypothesis that aggression may be more functional in sports teams than classrooms since it can be directed toward the opposition. Aggression may play less of a role in the social status of disliked peers in this setting and resulting in more similar levels of aggression between liked and disliked peers.

However, an alternative explanation may be that the disliked peers act in physically aggressive ways more infrequently in female sports teams than in classrooms. This seems like a plausible explanation since the physical aggression of liked peers were not perceived to differ between classrooms and sports teams for females. Liked and disliked peers were hypothesized to be perceived as more similar in physical aggression in sports teams compared to classrooms. Although this was the result for female participants, it was only due to lower perceived aggression of disliked peers and not to higher perceived physical aggression of liked peers. Furthermore, for male participants' perceptions, the differences between the settings were non-significant for both liked and 
Behaviours of liked and disliked adolescents 54

disliked peers even though a greater effect would have been expected for male participants due to research suggesting that males are more physically aggressive than females (Broidy, et al., 2003) and that physical aggression conforms to male gender norms (Doyle \& Paludi, 1998). Thus, the low physical aggression scores of females' disliked peers within sports teams may indicate that physical aggression is less common in female sports teams in general rather than the physical aggression of liked and disliked peers being perceived to be more similar because physical aggression is more accepted. Future research may conclude one of these possibilities is more plausible.

\section{Future Directions and Limitations}

The results of the present study have demonstrated that research of the behaviours of liked and disliked adolescents should consider social setting and gender. Future research is needed however, to help clarify the roles that these factors play. The possibility that sports teams may be a more positive environment generally, and the possible explanations for female participants' perceptions of low levels of physical aggression of disliked peers in sports teams mentioned earlier are only two questions the present study has raised. Other directions for future research include examining the degree to which children are disliked in different social groups, examining the likelihood that changes in social status from one setting to another are positive, and using a variety of methods besides peer perceptions.

The greater prosocial behaviour of peers from sports teams compared to classrooms suggests that sports teams may be a more positive environment for many adolescents. Future research should take into consideration the degree to which a child is liked or disliked within a setting. Participants in the present study were simply asked to 
Behaviours of liked and disliked adolescents 55 think of someone who was liked and disliked in each setting. One possibility is that children in one setting may be liked or disliked more intensely than in the other settings. The most disliked team members may face less intense rejection than the most disliked adolescents in classrooms settings. Possible differences between settings in the degree to which peers are liked or disliked may account for some of the results of the present study. In addition to different treatment of members of sports teams and classrooms, adolescents may also experience changes in their social statuses from one setting to another. As mentioned earlier, an average child in a classroom may find his or her behaviours in sports result in a lower social status. Others may find settings in which their behaviours result in an increase in social status. Furthermore, the behaviours of the target participants may change from one setting to another. Following target research participants as they enter new social settings would likely present an important perspective on the role of social factors in peer relations. The likelihood that a target experiences differences in his or her social status from one setting to another and considerations to ensure the change in social status is a positive one could be addressed.

Finally, future research needs to use a variety of methods to investigate the roles of gender and social setting in peer relations. The present study used participants' reports of their liked and disliked peers. Although the significant main effects of social status indicate that participants were able to effectively think about peers who were liked and disliked, they may not have been able to distinguish between the social settings as easily. Instead of thinking of a specific person for each setting, participants may have thought of liked and disliked peers more generally. Furthermore, participants may have compared peers from classroom and sports settings to peers within each setting rather than to a 
Behaviours of liked and disliked adolescents 56

more general population of peers. These possibilities would both result in an underestimation of the effects of social setting in the present study. Future research may find observational methods as opposed to peer ratings to be more powerful.

\section{Conclusion}

The present study met its purpose of considering the roles of social setting and gender in the behaviours of liked and disliked adolescents. The results suggested large differences between the liked and disliked adolescents with liked peers being perceived to display greater prosocial behaviour, athletic ability and less aggression than disliked peers. These results confirmed the hypotheses and met the first objective of the study - to replicate past research with an unconventional method.

The second and third objectives of the present study were also met. These objectives were to investigate differences between classroom and sports team social settings and to explore differences between male and female participants in the perceived behaviours of liked and disliked peers. Although the perceptions of the behaviours of liked and disliked peers generally followed the same pattern for male and female participants across the classroom and sports team settings, important differences were found. Differences between classroom and sports team settings regarding perceptions of prosocial behaviour and athletic ability, and interactions among the social setting, social status and gender variables regarding aggressive behaviour support the importance of considering both social and individual factors when studying peer relations.

The results of the present study suggest that children who experience problems with peers in one setting are likely to also experience problems in other settings. However, experiences with peers in different social settings appear likely to differ. 
Behaviours of liked and disliked adolescents 57 Participating in extracurricular activities which suitably match the children's interests and abilities may help children to develop more appropriate behaviours and may help them find peer groups which offer more positive experiences. For example, the results of the present study would suggest that a sports team would be appropriate for children who are athletically skilled and value the importance of sports. Children who participate in sports will likely be exposed to positive peers modeling prosocial behaviour and peers who share the value of participants' athletic skills. The present study supports the importance of considering social factors and gender when researching peer relations. Perhaps future research will be able to expand on this research and improve programs to help children and adolescents develop positive experiences with their peers. 
Behaviours of liked and disliked adolescents 58 References

Baumeister, R. F., \& Leary, M. R. (1995). The need to belong: Desire for interpersonal attachments as a fundamental human motivation. Psychological Bulletin, 117, 7190.

Baumeister, R. F., Twenge, J. M., \& Nuss, C. K. (2002). Effects of social exclusion on cognitive processes: Anticipated aloneness reduces intelligent thought. Journal of Personality and Social Psychology, 83, 817-827.

Bierman, K. L. (2004). Peer Rejection: Developmental Processes and Intervention Strategies. New York: The Guilford Press.

Bierman, K. L. (1986). The relation between social aggression and peer rejection in middle childhood. In R. J. Prinz (Ed.) Advances in Behavioral Assessment of Children and Families (Vol 2, p. 151-178). Greenwich CT: JAI Press.

Boivin, M., Dodge, K. A., \& Coie, J. D. (1995). Individual-group behavioral similarity and peer status in experimental play groups of boys: The social misfit revisited. Journal of Personality and Social Psychology, 69, 269-279.

Boivin, M., Hymel, S., \& Bukowski, W. M. (1995). The roles of social withdrawal, peer rejection, and victimization by peers in predicting loneliness and depressed mood in childhood. Development and Psychopathology, 7, 765-785.

Bredemeier, B. J., \& Shields, D. (1984). The utility of moral stage analysis in the investigation of athletic aggression. Sociology of Sport Journal, 1, 138-149.

Bredemeier, B. J., Weiss, M. R., Shields, D. L., \& Cooper, B. A. B. (1986). The relationship of sport involvement with children's moral reasoning and aggression tendencies. Journal of Sport Psychology, 84, 304-318. 
Behaviours of liked and disliked adolescents 59

Broidy, L. M., Nagin, D. S., Tremblay, R. E., Bates, J. E., Brame, B., Dodge, K. A., et al., (2003). Developmental trajectories of childhood disruptive behaviors and adolescent delinquency: A six-site, cross-national study. Developmental Psychology, 39, 222-245.

Burgess, K. B., Wojslawowicz-Bowker, J., Oh, W., Rubin, K. H., Booth-LaForce, C., \& Rose-Krasnor, L. (2006). The "Extended Class Play" measure of socialbehavioral risk and competence. Unpublished manuscript.

Chang, L. (2004). The role of classroom norms in contextualizing the relations of children's social behaviors to peer acceptance. Developmental Psychology, 40, 691-702.

Chase, M. A., \& Dummer G. M. (1992). The role of sports as a social status determinant for children. Research Quarterly for Exercise and Sport, 63, 418-424.

Chen, X., Rubin, K. H., \& Sun, Y. (1992). Social reputation and peer relationships in Chinese and Canadian children: A cross-cultural study. Child Development, 63, 1336-1343.

Coie, J. D. (1990). Towards a theory of peer rejection. In S. R. Asher \& J. D. Coie (Eds.), Peer Rejection in Childhood (pp. 365-401). Cambridge: Cambridge University Press.

Coie, J. D. (2004). The impact of negative social experiences on the development of antisocial behavior. In J. B. Kupersmidt \& K. A. Dodge (Eds.), Children's Peer Relations: From Development to Intervention (pp. 243-267). Washington: American Psychological Association. 
Behaviours of liked and disliked adolescents 60

Coie, J. D., \& Dodge, K. A. (1988). Multiple sources of data on social behaviour and social status in the school: A cross-age comparison. Child Development, 59, 815829.

Coie, J. D., Dodge, K. A., \& Coppotelli, H. (1982). Dimensions and types of social status: A cross-age perspective. Developmental Psychology, 18, 557-570.

Coie, J. D., \& Kupersmidt, J. B. (1983). A behavioral analysis of emerging social status in boys' groups. Child Development, 54, 1400-1416.

Doyle, J. A., \& Paludi, M. A. (1998). Sex and gender: The human experience (4th ed.). Boston: McGraw-Hill.

Evans, J., \& Roberts, G. C. (1987). Physical competence and the development of children's peer relations. Quest, 39, 23-35.

Gazelle, H. (2006). Class climate moderates peer relations and emotional adjustment in children with an early history of anxious solitude: A child X environment model. Developmental Psychology, 42, 1179-1192.

Gill, D. L., \& Deeter, T. E. (1988). Development of the sport orientation questionnaire. Research Quarterly for Exercise and Sport, 59, 191-202.

Gross, A. M., Johnson, T. C., Wojnilower, D. A., \& Drabman, R. S. (1985). The relationship between sports fitness training and social status in children. Behavioral Engineering, 9, 58-65.

Guerra, N. G., Huesmann, L. R., \& Hanish, L. (1995). The role of normative beliefs in children's social behaviour. In N. Eisenberg (Ed.), Social development (pp.140158). Thousand Oaks, CA: Sage Publications. 
Behaviours of liked and disliked adolescents 61

Hacker, C. (2003). Understanding why children participate in soccer. Retrieved Sept.

15, 2005, from http://www.footy4kids.co.uk/why_children_play_soccer.html.

Hartup, W. W. (1983). The Peer System. In P. H. Mussen (Series Ed.) \& E. M.

Hetherington (Vol. Ed.), Handbook of Child Psychology: Vol. 4, Socialization, personality, and social development (4th ed., pp. 102-196). New York: Wiley.

Hartup, W. W., Glazer, J. A., \& Charlesworth, R. (1967). Peer reinforcement and sociometric status. Child Development, 38, 1017-1024.

Johnstone, B., Frame, C. L., \& Bouman, D. (1992). Physical attractiveness and athletic and academic ability in controversial-aggressive and rejected-aggressive children. Journal of Social and Clinical Psychology, 11, 71-79.

Koslin, B. L., Haarlow, R. N., Karlins, M., \& Pargament, R. (1968). Predicting group status from member's cognitions. Sociometry, 31, 64-75.

Ladd, G. W. (2006). Peer rejection, aggressive or withdrawn behavior, and psychological maladjustment from ages 5 to 12: An examination of four predictive models. Child Development, 77, 822-846.

Lancelotta, G. X., \& Vaughn, S. (1989). Relation between types of aggression and sociometric status: Peer and teacher perceptions. Journal of Educational Psychology, 81, 86-90.

Levine, J. M., Moreland, R. L., \& Hausmann, L. R. (2005). Managing group composition: Inclusion and exclusion role transitions. In D. Abrams, M. A. Hogg \& J. M. Marques (Eds.), The Social Psychology of Inclusion and Exclusion (pp. 137-160). New York: Psychology Press. 
Behaviours of liked and disliked adolescents 62

Maccoby, E. E. (1990). Gender and relationships: A developmental account. American Psychologist, 45, 513-520.

Murphy, S. (1999). The Cheers and the Tears: A healthy alternative to the dark side of youth sports today. San Francisco: Jossey-Bass Publishes.

Newcomb, A. F., \& Bukowski, W. M. (1984). A longitudinal study of the utility of social preference and social impact sociometric classification schemes. Child Development, 55, 1434-1447.

Newcomb, A. F., Bukowski, W. M., \& Pattee, L. (1993). Children's peer relations: A meta-analytic review of popular, rejected, neglected, controversial, and average sociometric status. Psychological Bulletin, 113, 99-128.

Parker, J. G., \& Asher, S. R. (1987). Peer relations and later personal adjustment: Are low-accepted children at risk? Psychological Bulletin, 102, 357-389.

Parkinson, B., Fischer, A. H., \& Manstead, A. S. R. (2005). Emotion in Social Relations: Cultural, Group, and Interpersonal Processes. New York: Psychology Press.

Perry, D. G., Perry, L. C., \& Kennedy, E. (1992). Conflict and the development of antisocial behavior. In C. Shantz \& W. Hartup (Eds.), Conflict in Child and Adolescent Development (pp. 301-329). Cambridge: Cambridge University Press.

Pope, A. W., Bierman, K. L, \& Mumma, G. H. (1991). Aggression, hyperactivity, and inattention-immaturity: Behavior dimensions associated with peer rejection in elementary school boys. Developmental Psychology, 27, 663-671.

Prinstein, M. J., \& Cillessen, A. H. N. (2003). Forms and functions of adolescent peer aggression associated with high levels of peer status. Merrill-Palmer Quarterly, $49,310-342$. 
Behaviours of liked and disliked adolescents 63

Rodkin, P. C., Farmer, T. W., Pearl, R., \& Van Acker, R. (2000). Heterogeneity of popular boys: Antisocial and prosocial configurations. Developmental Psychology, 36, 14-24.

Stormshak, E. A., Bierman, K. L., Bruschi, C., Dodge, K. A., Coie, J. D., \& the Conduct Problems Prevention Research Group (1999). The relation between behaviour problems and peer preference in different classroom contexts. Child Development, $70,169-182$

Twenge, J. M., \& Baumeister, R. F. (2005). Social exclusion increases aggression and self-defeating behaviour while reducing intelligent thought and prosocial behaviour. In D. Abrams, M. A. Hogg \& J. M. Marques (Eds.), The Social Psychology of Inclusion and Exclusion (pp. 27-46). New York NY: Psychology Press.

Twenge, J. M., Baumeister, R. F., DeWall, C. N., Ciarocco, N. J., \& Bartels, J. M. (2007). Social exclusion decreases prosocial behaviour. Journal of Personality and Social Psychology, 92, 56-66.

Twenge, J. M., Catanese, K. R., \& Baumeister, R. F. (2002). Social exclusion causes selfdefeating behaviour. Journal of Personality and Social Psychology, 83, 606-615.

Unger, R. K. (1979). Toward a redefinition of sex and gender. American Psychologist, $34,1085-1094$.

Weiss, M. R., \& Duncan, S. C. (1992). The relationship between physical competence and peer acceptance in the context of children's sports participation. Journal of Sport and Exercise Psychology, 14, 177-191. 
Behaviours of liked and disliked adolescents 64

Williams, K. D., \& Govan, C. L. (2005). Reacting to ostracism: Retaliation or reconciliation? In D. Abrams, M. A. Hogg \& J. M. Marques (Eds.), The Social Psychology of Inclusion and Exclusion (pp. 47-62). New York: Psychology Press.

Wright, J. C., Giammarino, M., \& Parad, H. W. (1986). Social status in small groups: Individual-group similarity and the social "misfit." Journal of Personality and Social Psychology, 50, 523-536. 
Behaviours of liked and disliked adolescents 65

Appendix A-Letter Requesting Participation of Sports Team

June 20, 2007

To:

From: Geoff Wilton

Ottawa, ON

Dear

I am a graduate student in the psychology department at Carleton University working on my master's thesis. I am interested in children's peer relations, how they get along with other children in different social contexts. I am particularly interested in children's experiences with their peers in a sports context. For example, some children may have a more positive experience with their peers in a sports team than they do in a classroom. The purpose of this study is to examine the different types of behaviours associated with positive peer experience in a sports team (e.g. athletic ability) versus in a classroom (e.g. prosocial behaviour). My research is being conducted under the supervision of Dr. Anne Bowker, Professor of Psychology, Carleton University. I am seeking approval to include players from your sports club in this investigation.

Data will be collected for this study through the administration of questionnaires given to the players assessing their perceptions of the behaviours of liked and disliked team-mates and school classmates. These questionnaires will take approximately 25 minutes to complete and players will have the option to complete them at their leisure on a secure internet-based survey or as a pen-and-paper survey to be mailed to the researchers. The target participants will be male and female recreational and competitive athletes, ages 11 to 13 .

The study is in no way expected to harm or embarrass participants, or their peers. All information collected during the course of the study will be kept strictly confidential, and the identity of all athletes will remain anonymous. At no time will participants be named or identified in any way. If you so wish, the identity of the club may also remain anonymous.

Players and their parents will be free to discontinue participation in this project at any time during the course of the study, or to omit specific questions, without penalty. Each player's parent or guardian will be informed of the purposes and procedures, as well as the voluntary nature of this study, and will be asked to give their permission for their child to participate. Furthermore, I will not be making personal contact with the individual players, and will not interfere with practices or game procedures in any way other than to hand out the consent forms and facilitate filling out the questionnaires. After the study has been completed, information concerning its findings will be made available to all interested parties including players, parents, coaches, and club administrators. 
Behaviours of liked and disliked adolescents 66

The participation of your club in this project will be greatly appreciated as it will allow the collection of information pertaining to issues many adolescents struggle with every day and the possibility that some social groups such as sports teams offer more positive social experiences. It is only through the combined efforts of researchers and concerned youth organizations that quality scientific research can be done, and rewarding social experiences can be made available for all adolescents.

I am greatly looking forward to working on this project with your approval. If you have any questions please feel free to contact me (gwilton@connect.carleton.ca, 613-2740339) or my supervisor Dr Anne Bowker, Professor of Psychology (anne_bowker@carleton.ca, 613-520-2600 ext 8218). All aspects of this study will meet Canadian ethical standards as assessed by the Carleton University Ethics Committee for Psychological Research, chaired by Dr. Avi Parush, (520-2600, ext. 6026).

Yours sincerely,

Geoff Wilton 
Behaviours of liked and disliked adolescents 67

Appendix B-Informed Consent Form

\section{Dear Parents,}

Please consider having your child participate in an important research project. The following is an informed consent form. The purpose of an informed consent is to insure that you understand the purpose of the study and the nature of your child's involvement. The informed consent must provide sufficient information such that you have the opportunity to determine whether you agree to your child's participation in the study.

Present study: Perceived behaviours of Liked and Disliked Adolescents: Comparing Sports Team and Classroom Contexts.

Research personnel: The following people are involved in this research project and may be contacted at any time: Geoff Wilton (email: gwilton@connect.carleton.ca, phone: 613274-0339), or Dr. Anne Bowker (Faculty Sponsor, 520-2600 ext. 8218). Should you have any ethical or other concerns about this study then please contact Dr. Avi Parush, Chair, Carleton University Ethics Committee for Psychological Research, (520-2600, ext. 6026) or Dr. Anne Bowker (Chair, Dept. of Psychology, 520-2600, ext. 8218).

Purpose: The purpose of this study is to investigate your child's perceptions of peer behaviour in different contexts, comparing sports teams to classrooms.

Task requirements: Participants will complete brief questionnaires measuring the athletic competence, aggression, and prosocial behaviour of liked and disliked peers from sports teams and classrooms. Participants will also be asked about their own amount of experience in competitive sports: sports your child has played and the number of years playing sports.

Duration and locale: The questionnaires will take approximately 25 minutes to complete, and will be filled-out online.

Potential risk/discomfort: No harm, discomfort, or embarrassment is expected for participants of this study.

Anonymity/confidentiality: The data collected in this experiment are strictly confidential. All data are coded such that your name and your child's name will never be associated with the data.

Right to withdraw: You and your child have the right to withdraw from the study at any time without penalty. He or she may also choose to skip (i.e., not answer) questions for any reason without penalty.

I have read the above form and understand the conditions of my child's participation. My child's participation in this study is voluntary, and if for any reason, at any time, I wish to remove my child from the study, I may do so without having to give an explanation and with no penalty whatsoever. Furthermore, I am also aware that the data gathered in this study are confidential and anonymous with respect to my child's and my own personal identity. My signature indicates that I agree to my child's participation in the study.

Parent's Name: Parent's Signature:

Date: 
Behaviours of liked and disliked adolescents 68

Email Contact: Phone Contact:

Child's Name: Child's Birth Date:

Child's Gender:___ Child's Ethnic Background:

Researcher's Name: Researcher's Signature: 
Behaviours of liked and disliked adolescents 69 Appendix C-Child Online Consent Form.

Please enter your participant number provided in the email.

Please read the following statement and select the appropriate option if you wish to be in our study:

I understand that I have been asked to be in a research study that Geoff Wilton and Dr. Anne Bowker from Carleton University are doing about behaviours of people in sports and classrooms.

I know that if I agree to be in the study I will be asked to fill in some questionnaires about myself, and people I know in sports and classrooms.

I know that I do not have to be in the study, and that even if I start to take part in it I can quit at any time.

I know that I can ask any questions about the study before I participate.

I also know that my answers will be kept secret and will not be shown to anyone, not even to my teachers, my parents or my friends. Only Geoff Wilton and Dr. Bowker will know what I say on the questionnaire.

1. I AGREE to participate.

2. I DO NOT AGREE to participate. 
Behaviours of liked and disliked adolescents 70 Appendix D-Sport Experience Questionnaire.

We are interested in your experience playing competitive sports.

\begin{tabular}{|c|c|}
\hline & $\begin{array}{c}\text { Select all the sports you have played competitively with } \\
\text { an organized league, coaches, league games, standings, } \\
\text { tournaments, referees or judges, etc. }\end{array}$ \\
\hline Baseball & $\square$ \\
\hline Basketball & $\square$ \\
\hline Curling & $\square$ \\
\hline Cycling & $\square$ \\
\hline figure skating & $\square$ \\
\hline Football & $\square$ \\
\hline Golf & $\square$ \\
\hline Hockey & $\square$ \\
\hline martial arts & $\square$ \\
\hline Soccer & $\square$ \\
\hline Swimming & $\square$ \\
\hline Tennis & $\square$ \\
\hline Volleyball & $\square$ \\
\hline
\end{tabular}

What other sports have you played at a competitive level?

How many years have you participated in competitive sports?

Of the sports you have played competitively, which have you played the most?

How many years have you played this sport? 
Behaviours of liked and disliked adolescents 71 Appendix E-Peers' Behaviour Questionnaire.

\begin{tabular}{|c|c|c|c|c|c|}
\hline & $\begin{array}{c}\text { Nothing } \\
\text { like this } \\
\text { person }\end{array}$ & $\begin{array}{c}\text { Unlike this } \\
\text { person }\end{array}$ & $\begin{array}{c}\text { Neither } \\
\text { like nor } \\
\text { unlike this } \\
\text { person }\end{array}$ & $\begin{array}{c}\text { Like this } \\
\text { person }\end{array}$ & $\begin{array}{c}\text { Exactly } \\
\text { like this } \\
\text { person }\end{array}$ \\
\hline $\begin{array}{c}\text { 1. A person who interrupts } \\
\text { when other children are } \\
\text { speaking. }\end{array}$ & $\square$ & $\square$ & $\square$ & $\square$ & $\square$ \\
\hline $\begin{array}{c}\text { 2. A person with good ideas } \\
\text { for things to do. }\end{array}$ & $\square$ & $\square$ & $\square$ & $\square$ & $\square$ \\
\hline $\begin{array}{c}\text { 3. Other people think he or } \\
\text { she is good at sports. }\end{array}$ & $\square$ & $\square$ & $\square$ & $\square$ & $\square$ \\
\hline $\begin{array}{c}\text { 4. A person who loses } \\
\text { his/her temper easily. }\end{array}$ & $\square$ & $\square$ & $\square$ & $\square$ & $\square$ \\
\hline 5. Someone you can trust. & $\square$ & $\square$ & $\square$ & $\square$ & $\square$ \\
\hline $\begin{array}{c}\text { 6. He or she is good at most } \\
\text { sports. }\end{array}$ & $\square$ & $\square$ & $\square$ & $\square$ & $\square$ \\
\hline $\begin{array}{c}\text { 7. A person who gets into a } \\
\text { lot of fights. }\end{array}$ & $\square$ & $\square$ & $\square$ & $\square$ & $\square$ \\
\hline $\begin{array}{c}\text { 8. Someone who will wait } \\
\text { his / her turn. }\end{array}$ & $\square$ & $\square$ & $\square$ & $\square$ & $\square$ \\
\hline $\begin{array}{c}\text { 9. Most sports are easy for } \\
\text { him or her. }\end{array}$ & $\square$ & $\square$ & $\square$ & $\square$ & $\square$ \\
\hline \begin{tabular}{c} 
10. Someone who plays fair. \\
\hline $\begin{array}{c}\text { 11. Someone who spreads } \\
\text { rumors about other kids so } \\
\text { that people won't like them } \\
\text { anymore. }\end{array}$
\end{tabular} & $\square$ & $\square$ & $\square$ & $\square$ & $\square$ \\
\hline $\begin{array}{c}\text { 12. He or she has good } \\
\text { sports skills. }\end{array}$ & $\square$ & $\square$ & $\square$ & $\square$ & $\square$ \\
\hline $\begin{array}{c}\text { 13. A person who is too } \\
\text { bossy. }\end{array}$ & $\square$ & $\square$ & $\square$ & $\square$ & $\square$ \\
\hline $\begin{array}{c}\text { 14. Someone who helps } \\
\text { other people when they need } \\
\text { it. }\end{array}$ & $\square$ & $\square$ & $\square$ & $\square$ & $\square$ \\
\hline $\begin{array}{c}\text { 15. He or she is better at } \\
\text { sports than most of his or her } \\
\text { friends. }\end{array}$ & $\square$ & $\square$ & $\square$ & $\square$ & $\square$ \\
\hline $\begin{array}{c}\text { 16. Somebody who teases } \\
\text { other children too much. }\end{array}$ & $\square$ & $\square$ & $\square$ & $\square$ & $\square$ \\
\hline $\begin{array}{c}\text { 17. Somebody who picks on } \\
\text { other kids. }\end{array}$ & $\square$ & $\square$ & $\square$ & $\square$ & $\square$ \\
\hline
\end{tabular}


Behaviours of liked and disliked adolescents 72

\begin{tabular}{|c|c|c|c|c|c|}
\hline 18. Somebody who is polite. & $\square$ & $\square$ & $\square$ & $\square$ & $\square$ \\
\hline $\begin{array}{c}\text { 19. He or she plays sports } \\
\text { well. }\end{array}$ & $\square$ & $\square$ & $\square$ & $\square$ & $\square$ \\
\hline
\end{tabular}

